NBER WORKING PAPER SERIES

\title{
THE TRANSITION TO PERSONAL ACCOUNTS AND INCREASING RETIREMENT WEALTH: MACRO AND MICRO EVIDENCE
}

\author{
James M. Poterba \\ Steven F. Venti \\ David A. Wise \\ Working Paper 8610 \\ http://www.nber.org/papers/w8610 \\ NATIONAL BUREAU OF ECONOMIC RESEARCH \\ 1050 Massachusetts Avenue \\ Cambridge, MA 02138 \\ November 2001
}

This paper was written while Poterba was a visiting fellow at the Hoover Institution. We are grateful to the National Institute on Aging, the Hoover Institution, and the National Science Foundation for financial support, and to Gary Engelhardt, Bill Gale, Al Gustman, Syl Scheiber, Jon Skinner, Tom Steinmeier and participants in the Berkeley Department Seminar, the Stanford Public Economics workshop, and two NBER meetings for helpful comments. We also thank Dan Beller at the Pension and Welfare Benefits Administration of the United States Department of Labor for generous help in understanding the Form 5500 data. The views expressed herein are those of the authors and not necessarily those of the National Bureau of Economic Research.

(C) 2001 by James M. Poterba, Steven F. Venti and David A. Wise. All rights reserved. Short sections of text, not to exceed two paragraphs, may be quoted without explicit permission provided that full credit, including (C) notice, is given to the source. 
The Transition to Personal Accounts and Increasing Retirement Wealth:

Macro and Micro Evidence

James M. Poterba, Steven F. Venti and David A. Wise

NBER Working Paper No. 8610

November 2001

$\underline{\text { ABSTRACT }}$

Retirement saving has changed dramatically over the last two decades. There has been a shift from employer-managed defined benefit pensions to defined contribution retirement saving plans that are largely controlled by employees. In 1980, 92 percent of private retirement saving contributions were to employer-based plans and 64 percent of these contributions were to defined benefit plans. Today, about 85 percent of private contributions are to plans in which individuals decide how much to contribute to the plan, how to invest plan assets, and how and when to withdraw money from the plan. In this paper we use both macro and micro data to describe the change in retirement assets and in retirement saving. We give particular attention to the possible substitution of pension assets in one plan for assets in another plan, such as the substitution of 401(k) assets for defined benefit plan assets.

Aggregate data show that between 1975 and 1999 assets to support retirement increased about five-fold relative to wage and salary income. This increase suggests large increases in the wealth of future retirees. The enormous increase in defined contribution plan assets dwarfed any potential displacement of defined benefit plan assets. In addition, in recent years the annual "retirement plan contribution rate," defined as retirement plan contributions as a percentage of NIPA personal income, has been over 5 percent. This is much higher than the NIPA total personal saving rate, which has been close to zero.

Retirement saving as a share of personal income today would likely be at least one percentage point greater had it not been for legislation in the 1980s that limited employer contributions to defined benefit pension plans, and the reduction in defined benefit plan contributions associated with the rising stock market of the 1990s. It is also likely that the "retirement plan contribution rate" would be much higher today if it were not for the 1986 retrenchment of the IRA program.

Rising retirement plan contributions, as well as favorable rates of return on retirement plan assets in the 1990s, explain the large increase in these assets relative to income. Employee retirement saving under a defined contribution plan is easily measured and quite transparent to the employee. On the other hand, annual employee "saving" under a defined benefit plan is more difficult to measure. It is also less likely to be clearly understood by employees. The average annual saving rate under a typical 401(k) plan is roughly twice as high as the average saving rate under a typical defined benefit plan, when properly measured. In addition, the early retirement incentives inherent in the provisions of most defined benefit plans will tend to reduce the aggregate accumulation of defined benefit retirement assets relative to defined contribution assets, since defined contribution participants are likely to work longer and contribute for more years.

The micro data show no evidence that the accumulation of $401(\mathrm{k})$ assets has been offset by a reduction in defined benefit assets. Because annual "saving" is much greater under 401(k) than under defined benefit plans, assets at retirement after lifetime employment under a 401(k) plan would typically be much higher than under a defined benefit plan. In addition, a large fraction of new 401(k) enrollees retained defined benefit coverage, which probably further increased their retirement saving.

James M. Poterba

MIT and NBER

David A. Wise

Harvard University, NBER and Hoover Institution
Steven F. Venti

Dartmouth College and NBER 
The transition from employer managed defined benefit pensions to retirement saving plans that are largely managed and controlled by employees has been the most striking change in retirement saving over the last two decades. Individual managed and controlled retirement accounts, particularly 401(k) plans but also 403(b) plans for nonprofit organizations, 457 plans for state and local employees, the Thrift Savings Plan for federal employees, Keogh plans for self-employed workers, and Individual Retirement Accounts (IRAs), have grown enormously. Employer-provided defined benefit (DB) pension plans have declined in importance. In 1980, 92 percent of private retirement saving contributions were to employer-based plans; 64 percent of these contributions were to DB plans. In 1999, about 85 percent of private contributions were to accounts in which individuals controlled how much to contribute to the plan, how to invest plan assets, and how and when to withdraw money from the plans.

We consider the changes in the magnitude and the composition of saving for retirement over the last two decades. We begin with an analysis of aggregate data on retirement plan contributions. We then turn to micro data, describe patterns in these data, and try to reconcile these patterns with the aggregate data. We document the changes in aggregate retirement saving over the past twenty-five years and describe how these changes are related to the shift from employer-sponsored defined benefit plans to individual-controlled retirement saving. We then investigate whether the shift toward individual retirement saving, and the accumulation of retirement assets in these accounts, has been offset by a reduction in the assets in other retirement saving plans. In a series of earlier papers, summarized in Poterba, Venti, and Wise (hereafter 
PVW) [1996a and 1998a], we found large net saving effects of IRAs and 401(k)s. We emphasized the potential offsets between saving in self-directed retirement accounts, other forms of financial asset saving, and the accumulation of home equity. On balance we found little, if any, offset in these cases. More recently, Benjamin [2000] and Pence [2001] have also found little or no offset between $401(k)$ contributions and non-401(k) financial asset saving, although the latter study also found little evidence that $401(\mathrm{k}) \mathrm{s}$ increased total wealth. Recent work by Engen and Gale [2000] finds little offset among low earners, but more substantial offsets among high earners.

Much less attention has been directed to the possible offset of personal retirement assets by a reduction in the assets in DB pension plans. Engen, Gale, and Scholz [1994] found a negative relationship between participation in defined benefit pension plans and 401(k) plan assets in the 1987 and 1991 Surveys of Income and Program Participation. Papke [1999] concluded that between 1985 and 1992 about one-fifth of ongoing sponsors of DB plans terminated their plans and adopted or retained a conventional DC or a $401(\mathrm{k})$ plan. It is not clear from her analysis, however, whether the growth in $401(\mathrm{k})$ plans displaced DB plans. Papke, Petersen, and Poterba [1996] surveyed firms with $401(\mathrm{k}) \mathrm{s}$ and found that very few had terminated a preexisting defined benefit plan when they instituted their $401(\mathrm{k})$ plan. Their sample, however, may not have been representative of the broader population of firms.

More recently, Ippolito and Thompson [2000] combined Form 5500 data with information from the Pension Benefit Guarantee Corporation (PBGC) to study withinfirm changes in plans over time. They found little firm-level displacement of DB plans by $401(\mathrm{k})$ plans, and concluded that the replacement of a DB plan by a $401(\mathrm{k})$ is rare. 
Engelhardt [2000], based on data from the Health and Retirement Study (HRS), concludes that households eligible for a $401(\mathrm{k})$ have higher non-DB assets than households not eligible for a $401(\mathrm{k})$, but have the same level of assets when DB wealth is included. He interprets this as evidence of firm-level substitution of $401(\mathrm{k}) \mathrm{s}$ for DB pensions. However, as we explain below, the HRS does not allow accurate categorization of individuals into $401(\mathrm{k})$ eligible and non-eligible status.

Most recently, LeBlanc [2001] has estimated the reduction in contributions to the Registered Retirement Saving Program (RRSP) in Canada when persons are newly covered by an employer-provided DB plan. Based on a longitudinal panel of individual tax data, and using a difference-in-difference estimation procedure, he finds that for a dollar of DB plan saving, RRSP contributions are reduced by only about $\$ 0.15$.

Our analysis of these issues is divided into six sections. In the first section we consider aggregate data on the total stock of retirement wealth. The very large increase in total retirement assets relative to income over the past 25 years strongly suggests that the enormous growth in individual retirement assets has more than offset any displacement of asset growth in traditional DB pension plans.

In section two, we show that the "retirement plan contribution rate" is much greater than the personal saving rate reported in the National Income and Product Accounts (NIPA) in recent years. Our "retirement plan contribution rate" is determined by the retirement saving of current employees. The NIPA saving rate, in contrast, depends on the saving and consumption patterns of retirees as well as those who are currently working. We document the substantial growth over time in contributions to self-directed retirement saving programs, such as $401(k)$ plans. We also suggest that 
the retirement plan contribution rate was reduced by legislation restricting contributions to DB pension plans, as well as by the strong stock market performance of the late 1980s and 1990s and the associated reduction in required DB plan contributions.

In section three, we distinguish between retirement saving from the standpoint of an employee, and employer contributions to retirement saving plans. We argue that from the perspective of the employee, $401(\mathrm{k})$ retirement saving is likely to be much greater than traditional DB plan saving at most ages. We use data on accruing DB plan liabilities to compare $401(\mathrm{k})$ and DB plan saving rates, and conclude that the saving rate under a typical $401(\mathrm{k})$ plan is about twice that under a typical DB plan.

In section four, we begin to explore the possible substitution between different types of retirement plans. We use data from both the Department of Labor Form 5500 filings, and from the Survey of Income and Program Participation (SIPP). We find no evidence of strong substitution patterns between $401(\mathrm{k})$ participation and other retirement plans. Section five shows that further analysis of substitution, using data from the Health and Retirement Survey (HRS), supports the results in section four. A brief conclusion summarizes our findings.

\section{AGGREGATE DATA ON ASSETS IN RETIREMENT SAVING PLANS}

\subsection{Retirement Account Assets}

While it is not possible to link particular assets with particular motives for saving, for many households assets in retirement saving accounts are the best single indicator of the amount that they have saved for retirement. A number of factors are likely to 
contribute to variation in retirement assets. For example, one would expect that households with higher earnings would have more retirement assets. For a given level of aggregate earnings, a larger share of the working population near retirement age is likely to be associated with greater retirement assets. Variation in life expectancy and in the typical retirement age can also affect the stock of retirement assets. The "adequacy" of any given level of assets depends on the years of support the assets are expected to provide.

Our analysis begins with measures of aggregate retirement assets that are not adjusted for demographic trends. We then explain the likely effect of adjustment for demographic changes. Figure 1 shows the ratio of assets in all private retirement accounts--including DB plans, 401(k), other DC plans, IRAs, 403(b) plans, and Keogh plans--to private wage and salary earnings. ${ }^{1}$ This ratio increased more than five-fold between 1975 and 1998 , from 0.39 to 2.02 . The figure shows modest growth in the ratio of retirement assets to earnings through 1981, more rapid growth between 1982 and 1994, after the introduction of IRAs and 401(k) plans and during a period of positive stock market returns, and rapidly accelerated growth beginning in 1995, corresponding to large increases in equity market returns. Figure 1 also shows the ratio of assets in all retirement plans, the private plans as well as public sector plans, to wages and salaries. The trend is very similar to that for private plan assets alone.

Figure 2 shows private retirement assets disaggregated into several components. It shows that assets in DB plans continued to grow after the introduction

${ }^{1}$ Appendix 1 describes all of our data sources. 
of $401(k)$ and IRA plans, but that the bulk of the gain was in individual accounts. In this figure, $401(k)$ assets are included with other DC plans. There is no evidence of a decline in the assets in conventional employer-provided plans during the time period when assets in individual accounts were growing most rapidly.

The foregoing data alone cannot rule out the possibility of substitution, since we do not have data on the time path that other retirement plan assets would have followed in the absence of the growth in DC assets. To place the growth in DC assets into perspective, however, we note that if all contributions to personal retirement accounts between 1985 and 1998 had come at the expense of DB contributions, DB assets would have grown by a factor of 8.4 instead of 2.7 .

The private retirement assets in Figure 2 exclude assets in federal, state, and local retirement plans, and assets held by life insurance companies in retirement plans, that are also part of the retirement asset pool. ${ }^{2}$ Figure 3 shows the assets in private plans as well as the assets in these other plans. In 1999, about 40 percent of all retirement assets were in federal, state and local, and insurance plan funds.

Retirement account assets support current retirees, as well as future retirees. Although we are unable to distinguish the assets held by current retirees from those held by the working-age population, we suspect that the increase in these assets represents a large upward trend in the assets of future retirees.

\subsection{Housing and Other Non-Retirement Assets}

${ }^{2}$ The Flow of Funds accounts defines the latter series as including "assets of private pension plans held at life insurance companies, such as guaranteed investment contracts and variable annuity plans, that are managed for the benefit of individuals who are not separately identified to the insurance companies." 
Aside from promised Social Security benefits, housing equity is the most important asset of a large fraction of Americans. Unlike the increase in retirement account assets, however, there has been no increase in housing equity relative to income over the past two and one-half decades. Figure 4 shows housing equity as a fraction of disposable income from 1975 to 1998 . The ratio increased about 25 percent between 1975 and 1989, but by 1999 it was essentially at the same level as in 1975 . The figure also shows non-retirement-non-home-equity net worth as a share of disposable income. This ratio decreased and then increased between 1985 and 1999 . The increase between 1975 and 1999, 27 percent, was not nearly as great as the increase in retirement assets over this period.

\subsection{Retirement Assets and Demographic Trends}

The growth of retirement assets relative to income may be "explained" by a number of changes. These include the advent of new retirement saving vehicles, as well as other factors such as demographic change. Changes in three features of the population--demographic composition, mortality rates, and labor force participation-have likely contributed to the rise in retirement assets relative to income. We describe each of these changes, although we do not attempt a formal adjustment of retirement wealth to correct for these changes.

The increase in life expectancy at retirement age is the first substantial change that may have contributed to rising retirement assets. In 1975, life expectancy for a U.S. man at age 62 was 15.5 years, while that for a woman was 20.3 years. By 1997 , male life expectancy at age 62 had increased to 17.6 years, while female life expectancy had risen to 21.4 years. For men, this implies a 13.5 percent increase in 
the number of years that need to be supported with retirement resources, beginning at age 62. For women, the change was 5.4 percent. These proportional changes provide a crude measure--crude, because they do not reflect the potential role of risk and the prospect of drawing down resources too quickly--of the increase in retirement resources that would be needed to offset improved longevity. These changes might account for an increase in resources of roughly ten percent, much less than the actual growth of retirement assets relative to income.

The second important demographic change that might have contributed to rising retirement assets was the aging of the labor force. Translating information on the age structure of the population into predictions about the wealth to income ratio requires detailed information on saving by age, yet there is no agreement on the relative importance of life-cycle, precautionary, and other factors in saving decisions. In 1975, the average age of those over the age of 20 in the U.S. population was 44.6 years. For men, the average age was 43.9 years. Between 1975 and 1985 the average age of those over 20 actually declined, to 44.3 years for the entire population and 43.5 years for the male population. This reflected the entry of the "baby boom" cohorts into the 20plus age group. By 1998, the working age population had grown older: the average age of all 20-plus persons was 45.5 years, and that of 20 -plus men was 44.8 years. Thus between 1985 and 1998, the average age of the adult population rose by just over one year. Similarly, the the average age of those in the labor force in 1985 was 38.5 years, while in 1998, it was 40.3 years.

These data on the population and labor force age structure suggest that by the late 1990s, those who were in their earning years were a older, and had fewer 
remaining years of work to accumulate assets for retirement, than those in the working population in the 1970 s and early 1980 s. This may also have induced a rise in retirement assets.

The final change that may have affected retirement assets is the shifting age of retirement in the U.S. population. During the 1980s and 1990s, these changes were modest by comparison to earlier decades. Burtless and Quinn (2000) present detailed information on age-specific labor force participation rates for U.S. men in 1970, 1984-5, and 1998-9. Their data show a sharp decline in labor force participation rates between 1970 and 1984-5, but relatively little decline subsequently. The participation rates for 1998-99 were virtually identical to those in 1984-85. At ages above 65 , the labor force participation rate in the late 1990s was greater than that in the mid-1980s. There is no systematic difference in labor force participation rates at younger ages. Labor force participation rates for women in their early 60 s increased between the mid-1980s and the late 1990s, as cohorts of women with greater labor force participation rates when they were younger entered the retirement-age cohort.

Changes in retirement ages are therefore not likely to account for substantial changes in retirement wealth relative to income during the last two decades.

Demographic factors-shifting age structure and lengthening life expectancy--seem likely to account for modest increases in retirement assets, but are unlikely to account for more than a small fraction of the large changes we observe.

\section{PLAN CONTRIBUTIONS \& THE "RETIREMENT PLAN CONTRIBUTION RATE"}

The accumulation of retirement assets depends on the inflow of contributions, the 
payout of benefits, and the return on invested assets. Figure 5a shows private pension plan contributions, which increased almost six fold between 1975 and 1999, while Figure $5 \mathrm{~b}$ shows contributions to all retirement plans. Neither of the series include contributions to privately held pensions plans administered by insurance companies, which hold about 9 percent of the assets in all pension plans. Private plans include selfdirected plans such as 401(k) plans and IRAs. IRA contributions exclude rollovers, while IRA assets include assets "rolled-in" to these accounts.

The pronounced "hump" in retirement plan contributions between 1982 and 1986 corresponds to the beginning and subsequent retrenchment of the IRA program. The pattern strongly suggests that IRA contributions during this period were not offset by a reduction in other forms of retirement saving. Indeed, the rate of increase of non-IRA retirement saving was the same in the $1982-85$ period as in prior years. This pattern suggests that the total pool of assets in retirement plans would likely be much greater today if the IRA program had not been limited in 1986.

Figure $6 a$ shows both private and total retirement plan contributions scaled by disposable income. Figure $6 \mathrm{~b}$ shows plan contributions over wage and salary earnings. In both figures, private contributions are scaled by private earnings, while all contributions are scaled by all wage and salary earnings. We define these ratios as "retirement plan contribution rates." They measure the proportion of current earnings that is saved in retirement accounts by current employees. The contribution rates do not account for retirement plan earnings on existing assets, or for withdrawals from these plans. Below, we compare retirement plan contribution rates to NIPA national saving rates. 
Figures $6 \mathrm{a}$ and $6 \mathrm{~b}$ show that "retirement plan contribution rates" are remarkably stable over most of the period. Scaled by personal disposable income, the private plan contribution rate was about 3.5 percent in 1975 and in 1999, and the contribution rate for all plans varied between 5 and 6 percent for most of the period. When scaled by private and by all wage and salary earnings, the contribution rates are also stable, although they are greater than the rates scaled by personal disposable income. The retirement plan contribution rate for all plans, including those in the federal and state and local government sector, is near eight percent for most of the period, or about two percentage points higher than the rate for the private sector alone.

The relative stability in the retirement plan contribution rates was broken only by the large increase in the plan contribution rate when the IRA program was initiated, and a decrease when the program was curtailed in 1986. For example, relative to earnings, both the private and the all plan rates are about 2 percentage points higher during the IRA period-over 8 and 10 percent, respectively.

\subsection{Time Series Changes in the "Retirement Plan Contribution Rate"}

The relative stability of the retirement plan contribution rate conceals fluctuations in some of the factors that affect this rate. Contributions to private defined-contribution type plans increased sharply over the 1975-1999 period, while DB contributions varied widely. At the end of this period, DB plan contributions were only slightly higher than at the beginning.

Retirement plan contributions are the product of the number of participants and the average contribution per participant. Figure 7 shows the sum of the number of active 
participants in all defined benefit and defined contribution plans. ${ }^{3}$ It illustrates in particular the rapid growth of $401(\mathrm{k})$ plans. These plans, which first became available in 1982, grew to almost 38 million participants by 1997 . While $401(\mathrm{k})$ plan participation grew in the 1980s and 1990s, participation in DB plans declined from about 30 million in 1984 to about 23 million by 1997. Participation in non-401(k) DC plans increased until about 1986 and then declined, ending the period about 30 percent higher than at the beginning. There is a clear "IRA effect" on plan participants, as well as plan contributions, in the early 1980s. In total, the number of plan participants increased from about 39 million in 1975 to over 80 million in 1997.

Figure 8a shows contributions per participant in DB, DC, and 401(k) plans. Figure $8 \mathrm{~b}$ shows IRA and $401(\mathrm{k})$ contributions, while Figure $8 \mathrm{c}$ shows contributions to Keogh plans. DB contributions per participant fluctuated substantially during the last two decades, and they were about 40 percent higher at the end of the period than at the beginning. Non-401(k) DC contributions per participant increased about two-fold over the period, and on average were higher than DB contributions. Over the past fifteen years contributions per participant to 401 (k) plans were, on average, twice as large as contributions per participant to DB plans. Contributions to 401(k)s increased almost 50 percent between 1982 and 1996 alone. ${ }^{4}$ During the "unrestricted" IRA period, 1982-

${ }^{3}$ These data, from Form 5500 filings and IRS tabulations of tax returns, show the number of persons participating in each type of retirement saving plan. Many persons participate in more than one plan, so the total number of participants overstates the number of persons who participate in at least one plan. For 401(k) plans, participants include all persons eligible to contribute, regardless of actual contributions.

${ }^{4} 401(\mathrm{k})$ contributions are calculated by dividing total contributions to $401(\mathrm{k})$ plans by the total number of employees eligible to contribute, not the number that actually 
1986, IRA contributions on average were greater than $401(\mathrm{k})$ contributions.

Keogh contributions, although a small proportion of total retirement saving, increased enormously between the early 1980s and late 1990s. There is a rise of more than 200 percent between 1981 and 1986, when the Economic Recovery Tax Act of 1981 raised Keogh contribution limits from $\$ 7500$ to $\$ 15000$.

Figure 9 shows the trend in the number of participants in all plans combined and the trend in average contributions per participant. These two trends together yield the increase in total contributions shown above. The participation numbers reflect substantial double counting, since many individuals participate in more than one plan. The increase in average contributions per unique covered employee would be substantially higher than the increase shown in Figure 9.

\subsection{DB Contributions and the Retirement Plan Contribution Rate}

Figure 10 shows an index of defined benefit plan contributions per participant. It also shows an index for the number of participants, and the flow of contributions, to these plans. There are at least three reasons for the erratic variation in contributions to DB plans. The first is the slight rise and then steady decline in the number of active participants (current employees) in DB plans over the 1975-98 period. The number of total participants, including retirees, rose throughout the period.

A second is the link between returns on DB plan assets and current funding decisions. Benefits promised by DB plans are prescribed by a formula, which is

make contributions. There is much less change during this period in the participation rate of 401(k) eligibles, conditional on eligibility, than in the eligibility rate. Most of the change in the number of contributors is therefore due to changes in eligibility. 
typically based on years of service and final salary. The promised benefits are a liability of the firm, and the firm must insure that assets held in the plan are sufficient to cover this liability. Other things equal, a rise in investment returns increases DB asset balances relative to obligations, thereby reducing the need for additional contributions. Bernheim and Shoven [1988] discuss this feature of DB funding.

A third reason for the fluctuation in DB contributions is the series of legislative changes that limited the level of benefits that could be funded under DB plans and discouraged firms from over-funding their pension plans. Prior to 1986, firms could fund their DB plans to a level greater than their legal liability. A series of laws beginning with a 10 percent reversion tax, which was part of the Tax Reform Act of 1986, put stricter limits on funding. Ippolito [2001] estimates that in the absence of various funding restrictions, DB pension assets in 1995 would have been 28 percent higher. Schieber and Shoven [1997] report that when the limits on contributions to over-funded plans that were part of the Omnibus Budget Reconciliation Act of 1987 took effect, 48 percent of a sample of large pension plans were precluded from making further contributions.

Our analysis of DB contributions, relative to contributions to other plans, is directed at understanding how fluctuations in DB contributions affect the retirement plan contribution rate. While developing a precise estimate is an unrealistic target, we try to place a lower bound on the effect of movements in DB plan contributions on the retirement plan contribution rate.

Total DB contributions are the product of the number of DB plan participants and the average contribution per participant. Fluctuations are due largely to movements in the contribution per participant. Figure 11 provides information on DB, DC, and Keogh 
contributions per participant over the 1975-1997 period. It shows that the wages of wage and salary workers increased 150 percent over this period. DC plan contributions per participant increased about 150 percent as well, as one would expect if contributions were a proportion of wage earnings. On the other hand, DB contributions per participant fluctuated substantially, and on average fell relative to wages.

Suppose that there had been no legislation limiting contributions to DB plans, that market returns had not affected DB contributions, that life expectancy at retirement had been constant, and that there were no changes in the demographic structure of the workforce covered by DB plans. If the returns on DB plan assets were in line with expectations, one might have expected DB contributions per participant, relative to wages, to remain roughly constant. Given rising life expectancy and an aging workforce, one might have expected contributions per employee to increase relative to wages.

To explore the effects of legislative and return-induced downward pressures on defined benefit plan contributions, we construct a "what if" scenario. Considering the private sector only, suppose that DB contributions per employee had increased at the same rate as wages in every year after 1977 . Figure 12 shows the private retirement plan contribution rate under this counterfactual, together with the actual rate. The saving rate under this counterfactual assumption was one percentage point higher than the actual rate at the end of the period. In the years when the DB contribution rate was at its lowest, the counterfactual saving rate was close to 2 percentage points higher than the actual rate. This counterfactual suggests that legislative changes like those in 1986, and unexpectedly favorable returns on DB plan assets, probably reduced the private retirement plan contribution rate by a substantial amount. 
The aggregate data also suggest that the retirement plan contribution rate would have been substantially higher were it not for the curtailment of the IRA program. Between 1982 and 1985, IRA saving added approximately 2.3 percentage points to the retirement plan contribution rate. Now it accounts for only 0.3 percentage points.

In summary, aggregate retirement assets increased dramatically over the past two decades. All else equal, this reduces the likelihood that the rise of assets in DC retirement plans was offset by a reduction of assets in DB plans. This conclusion is consistent with the findings in previous studies using household data, which show increases in individual financial assets with the advent of $401(\mathrm{k})$ and IRA plans, and with the evidence that we present below. The decline in DB plans was probably due to many factors other than the growth of DC plans. Gustman and Steinmeier [1992], for example, find that at least half of the trend in DB plans from 1977 to 1985 "is due to a shift in employment mix towards firms with industry, size, and union status that have historically been associated with lower defined benefit rates." Ippolito [1995] concludes that "about half of the shift is attributable to a loss of employment in large unionized firms where DB plans are used intensively."

\subsection{NIPA Saving and the Retirement Plan Contribution Rate}

Contributions to retirement plans as a proportion of either wages and salaries or personal disposable income have substantially exceeded the NIPA personal saving rate in recent years. In the NIPA, saving equals disposable income, less consumption. This definition implies that increases in measured income increase saving, and increases in measured consumption decrease saving. Contributions to pension plans are treated as income in the NIPAs, so these contributions increase saving. Interest and dividends 
received by pension plans are also imputed as a component of income, and pension plan management fees are charged as a consumption outlay.

Neither capital gains on pension assets, nor distributions from pension plans, are included in NIPA income. If distributions from pension plans are partly consumed, however, the net effect of pension distributions will be to raise consumption and therefore, without any corresponding increase in income, to reduce NIPA saving.

The NIPA treatment of pensions can be illustrated with an example. Consider an employee who contributed to a 401(k) plan in 1982. Assuming that the contribution was made from income earned in that year, and reduced the contributor's consumption in 1982, the act of contributing would have raised personal saving in 1982. If the 401(k) assets were invested in non-dividend paying stocks, the internal build-up in their value would not have contributed anything to NIPA income in any year after 1982, until the date of distribution. ${ }^{5}$ Assume that the assets were distributed from the $401(\mathrm{k})$ plan in 2001. At that point, there would be no increase in NIPA income. If the beneficiary of the distributions raised consumption as a result of these distributions, the net effect would be higher consumer spending and therefore lower saving. With large capital gains between 1982 and 2001 , the distribution is likely to be very large relative to the initial contribution in 1982. Lusardi, Skinner, and Venti [2001] estimate that in 1999, the NIPA accounting of DB pension transactions alone reduced NIPA personal saving by almost $\$ 55$ billion. Figures 13 and 14 show that in recent years, distributions from DB plans and IRAs have

${ }^{5}$ The U.S. Department of Labor [1999] reports that in 1996, interest and dividends on $401(\mathrm{k})$ assets totaled $\$ 20.7$ billion, while contributions were $\$ 104$ billion and capital gains were $\$ 129.3$ billion. 
far exceeded contributions to these plans. ${ }^{6}$

The growth in retirement plan assets during the last decade highlights the limitations of the current NIPA treatment of pension saving. Gale and Sabelhaus (1999) and Reinsdorf and Perozek (2000) discuss limitations of the current definition of personal saving other than those associated with pensions. The distortions in the NIPA personal saving rate that result from the treatment of pension income will only become worse in the future. PVW [2001], for example, project that average 401(k) balances for the cohort retiring in 2025 will be roughly ten times greater than the balances for those who retired in the mid-1990s.

\section{RETIREMENT PLAN CONTRIBUTIONS VERSUS EMPLOYEE SAVING}

In this section we compare lifetime saving under an illustrative DB plan to that under a DC plan. We show that the pattern of retirement asset accumulation under the two plans is very different, and we note that an employee's perception of retirement saving under the two plans is likely to be very different as well. In addition, the early retirement incentives inherent in many DB plans suggest that DB plan participants will retire earlier than DC participants, and thereby will accumulate less in retirement assets. We then discuss implications of these findings for the comparison of individual assets in

${ }^{6}$ Until 2000, the treatment of public pensions in NIPA was almost the reverse of the treatment of private pensions. Employee contributions to the federal civilian retirement plan, state and local pension plans, and Social Security were not included in income, while benefits from these plans were counted as income. Employee contributions thus reduced saving. If benefits were fully spent, the resulting increase in consumption would precisely offset the increase in income associated with the benefits and saving would not be affected. Since 2000 , public and private pensions are treated the same in the NIPA. 
DB and DC plans, as well as the aggregate accumulation of pension assets, and consider empirical evidence on asset accrual in DB plans.

\subsection{Contributions vs. Saving: A Conceptual Framework}

Contributions to traditional non-401(k) DC plans are typically a constant percentage of employee earnings and are primarily funded by employer contributions. Contributions to $401(\mathrm{k})$ programs are also proportional to earnings, but the precise relationship between earnings and contributions depends on each firm's match rate and contribution limit, as well as on the saving choices of participants. About one-third of all 401(k) contributions are made by employers and two-thirds by participants.

In both 401(k) plans and other types of DC plans, contributions by employers and employees are easily observed by participants, making it unlikely that there are any differences between contributions to these plans and the amounts individuals perceive as "saved." This is not true for saving through DB plans. The annual DB "saving" that can be ascribed to a given plan participant may be very different from the employer contribution per participant. The amount a DB plan participant perceives to be saved on his or her behalf may be very different from the actual saving, as well as from the employer contribution to the plan.

Similarly, a participant's DB pension wealth is not easily observed and is difficult to determine. It is the discounted value of promised future benefits accrued to date. The annual personal DB saving rate is the change in promised benefits associated with working another year under the DB plan. ${ }^{7}$ Because most DB plans are "back-loaded,"

${ }^{7}$ The measure of accrued DB pension wealth that we use corresponds to the firm's current, or terminal, liability. Firms also compute projected liabilities, which use a 
this annual benefit accrual is typically very small for young workers and much larger for older workers, particularly as they approach the plan's early retirement age.

Unless the specific features of a DB plan are known, it is not possible to calculate saving rates at different ages under the plan. This makes it difficult to compare personal saving--from the perspective of the participant--under DB and DC plans. We present a simple framework to fix these ideas and to compare DC and DB saving rates.

For a person covered by a DB plan, saving is defined in terms of promised future retirement benefits. The increment to future retirement wealth is the change in accrued future benefits associated with working another year at the firm. Current saving is the present value of this accrual. DB saving is defined by a formula that determines benefits in the future, while DC saving is defined by the current contribution. In a DC plan, the increment to future retirement wealth is determined by the future value of the current contribution; that depends on the intervening rate of return on the plan assets.

In a simplified case, DB benefits are given by $B_{t}=8 W_{t} s$, where 8 is is a parameter of the plan, typically between 0.01 and 0.02 , and $W_{t}$ denotes earnings in year $t$, and $s$ is the number of years of service that the employee has in year $t$. After s years of employment, this is the accrued benefit promised at the normal retirement age, say 65 . If the employee leaves the firm after s years, future benefits at retirement are given by this formula. The change in B with another year of employment is given by

$$
\Delta B_{t}=\lambda\left[W_{t}+s(d W / d t)\right]=(w s+1) W_{t} \cdot \lambda
$$

forecast of future wage growth to value the future cost of years of service accrued to date. 
where $w$ is the annual rate of increase in earnings. The change in future pension wealth is given by this change in benefits, times the annuity value of a dollar at the retirement age of $65, A(65)$. Thus in the DB case, the increase in future retirement wealth associated with working another year is $) \mathrm{DBPW}=(w s+1)^{*} \mathrm{~W}_{t}{ }^{*}{ }^{*} \mathrm{~A}(65)$. Saving at age $\mathrm{t}$ under the DB plan, which can be compared to DC saving at age $t$, is this amount discounted back to age $t$. This accrual is an increase in the DB plan obligation that must be funded by the employer.

The ratio of the change in future retirement wealth associated with working another year under the DC plan, to the change in wealth from working another year under the DB plan is given by

$$
\frac{\triangle D C P W(t)}{\triangle D B P W(t)}=\frac{k W_{t}(1+r)^{65-t}}{(w s+1) W_{t} \lambda \cdot A(65)}=\frac{(1+r)^{65-t}}{(1+w s)} \frac{k}{\lambda \cdot A(65)}
$$

Note that ) DCPW depends on the market rate of return but not on the rate of increase in the wage rate, which affects ) DBPW. The market rate of return may affect ) DBPW through the $A(65)$ term. Suppose that $8=.015$, that $k=.10$, and that $A(65)=8$. Suppose also that people work from age 25 to age 65 . Then the ratio ) DCPW/) DBPW is $\left[(1+r)^{65-t} /(1+w s){ }^{*}[.10 / .12]\right.$. Suppose further that $r=0.09$ and $w=0.05$. At one year of employment the ratio is 20.04 , at 20 years it is 2.05 , and at 40 years it is 0.24 . DC wealth accrues early in the working life and DB wealth accrues late--it is "back-loaded". Most actual DB plans are not as simple as the one considered above. Actual accruals depend on the specific provisions of the DB plan. An employee is usually not 
vested in the plan before working some minimum number of years. ${ }^{8}$ DB saving is zero prior to vesting. In addition, most DB plans have an early retirement age (often 55), which is an important determinant of the accrual pattern. After the early retirement age, benefit accrual typically declines (often becoming negative), creating an incentive to retire early. The more complicated accrual patterns under these circumstances, and the associated incentives to retire, are described in detail in Kotlikoff and Wise [1987, 1988, 1989a, 1989b]. Lazear [1985] proposed that firms use these incentives to induce older workers-paid more than their marginal product-to retire. In the illustration below we use a typical plan, similar to a plan described in Kotlikoff and Wise [1989b], that incorporates a substantial incentive to retire after the early retirement age.

Suppose the DB plan has vesting after 5 years of service, early retirement at 55 , normal retirement at 65 , and an early retirement discount factor of 3 percent per year. The factor 8 is set at 0.013 . Table 1 shows saving at selected ages under this DB plan and under a $401(\mathrm{k})$ plan with a nine percent contribution rate. In this example, the nominal rate of growth of earnings declines from 7 percent per year at age 25 to 1 percent at age 65 . These earnings should be thought of as the historical earnings of persons now approaching retirement. The associated saving should be thought of as the saving of workers covered under the DB or the $401(\mathrm{k})$ plan over a working lifetime. ${ }^{9}$ The table shows three measures of saving: saving as a proportion of earnings at age $t$

${ }^{8}$ This is also true for some $401(\mathrm{k})$ plans in which the employer matching contribution is subject to a short vesting requirement.

${ }^{9}$ Workers now approaching retirement could only have been covered by a $401(\mathrm{k})$ plan for about two decades. 
(columns 3 and 4), saving in dollars at age t (columns 5 and 6 ), and the associated increment to wealth at age 65 (columns 7 through 10).

Table 1, column (4) shows $401(\mathrm{k})$ plan saving as a percent of earnings. At age 25 for example, nine percent of earnings is contributed to a DC account. The dollar amount, $\$ 831$, is shown in column (6). At a 9 percent market rate of return, the $\$ 831$ would grow to $\$ 26,089$ by age 65 , as shown in column (8). At age 45 , nine percent of earnings is $\$ 2,422$ and this amount grows to $\$ 13,572$ by age 65 . The total accumulation of assets under the DC plan will be $\$ 575,970$, by age 65 , if the employee continues to work and to make contributions until that age. This value is shown in the last row of column (8). Columns (9) and (10) show the increment to assets at retirement if the employee works until ages 55 and 60 respectively. The total accumulation of assets at these ages is $\$ 221,182$ and $\$ 362,205$, respectively.

The calculation of saving under the DB plan is more complicated. There is no saving in the DB plan until the employee is vested, which occurs at age 30 . Much more important are the provisions that determine pension accrual at later ages. Like the typical DB plan, the provisions of the DB plan used in this illustration discourage work past the early retirement age of $55,{ }^{10}$ while providing a strong incentive to stay at the firm until the early retirement age. Indeed the accrual of pension benefits is negative after age 55. Figure 15 shows this accrual pattern (saving) and the related incentive effects.

${ }^{10} \mathrm{HRS}$ data show that 29.8 percent of all workers qualify for early retirement before age 55, another 44.7 percent are eligible at exactly age 55, and only 14.8 percent qualify for early retirement after age 60 . The average early retirement age is 54.2 and the average age of normal retirement is 61.3. See Gustman and Steinmeier [2000a]. 
In this plan, the value of future DB pension benefits is maximized if receipt of benefits begins at age 55 . Consider, for example, saving at age 45 . The increment to promised future pension wealth, shown in column (7), is $\$ 4,554$, if receipt of benefits begins at age 55. After age 55, the three percent increment in benefits for each year that benefit receipt is delayed is not enough to offset the receipt of benefits for one fewer year. For each year benefit receipt is delayed after 55 , the present value of retirement benefits declines. This is the common feature of DB plans that encourages retirement after the early retirement age.

The dollar saving shown in column (5) at age 45 is $\$ 2,097$. This is the increment to assets at age 55 , discounted back to age 45 at 9 percent. ${ }^{11}$ As a proportion of the wage, DB saving, shown in column (3), is 7.8 percent at age 45 . If the DB employee remained in the firm until age 55 and then started to receive benefits, the value of lifetime benefits would be $\$ 102,911$.

Notice that at age 45 , for example, DB saving is only moderately less than DC saving- $\$ 2,097$ versus $\$ 2,422$. Yet the increment to total wealth at retirement is $\$ 4,554$ under the DB plan, while it is $\$ 13,572$ under the $401(\mathrm{k})$ plan, assuming that the

${ }^{11}$ We realize that in principal the discount rate applied to future DB benefits need not be the same as the market return earned on DC contributions. However, there is no clear way to measure the risk under each type of plan, and thus no obvious way to make a risk adjustment to the discount rates. Employees covered by DC plans face investment risk, but in DB plans most of this investment risk is borne by employers. Conversely, as a consequence of job change or job loss, employees covered by DB plans face the risk of losing a large fraction of the benefits they would accrue without job change. The erosion of benefits that results from job change is much less severe under DC plans. The average discount rate used by DB plans in Form 5500 reports was 7.77 percent in 1997. For simplicity in this illustration we let the discount rate equal the assumed rate of return. 
employee works until 65 . The difference in the increment to wealth at retirement is simply due to the difference in the assumed age of receipt of benefits. This is taken to be age 55 under the DB plan, since that is the age that maximizes benefits under the DB plan. The increment to DC wealth at age 55 (from saving at 45 ) is $\$ 5,733$, as shown in column (9).

Over a working life, the maximum present discounted value of future DB benefits is achieved if the receipt of benefits begins at age 55. At that age, the present value of future benefits is $\$ 102,911$. Total accumulation in the $401(\mathrm{k})$ plan at that age is $\$ 221,182$. Accumulation of assets in DB and DC plans, assuming retirement at 55 under both plans, is shown in Figure 16. But if the DC employee continues to work until 65 , the accumulation in the DC plan increases to $\$ 575,970$. The DC employee continues to make contributions at 9 percent of earnings, and assets accumulated at age 55 continue to grow at 9 percent.

For the DB employee, however, benefits grow much more slowly after the early retirement age. In our example, the nominal annual DB benefit continues to increase because of earnings growth and additional years of service. In addition, benefits are higher because they will be received for fewer years, but the increase is not enough to offset the fewer years of benefit receipt. This is reflected in the reduction in DB saving beginning at age 55 , shown in columns (3), (5), and (7) of Table 1 . The benefit at 55 is determined by the promised benefit at 65 discounted at 3 percent. That is, the adjustment for taking benefits before 65 -and thus receiving benefits for more years-is only 3 percent per year. Thus when the receipt of benefits is delayed, say until 65 , the benefit is increased by only 3 percent for each one-year reduction in the number of years 
benefits will be received. By age 65 , pension wealth in age 65 dollars is $\$ 181,458$. The increase between 55 and 65 is not enough to offset the reduction in the number of years benefits will be received.

Figure 17 shows the accumulations of assets under DB and DC plans, assuming retirement at age 65. In current dollars, DB pension wealth grows by a factor of 1.76 between 55 and 65 , while $\mathrm{DC}$ wealth grows by a factor of 2.64 . At age $55, \mathrm{DC}$ assets are 2.12 times as much as DB assets. If employees work to age 65, DC assets are 3.17 times as much as DB assets.

The assumption underlying Figure 17, that DB plan participants work until age 65, will tend to understate the difference between DB and $401(\mathrm{k})$ accumulation profiles. Given DB incentives to retire early, few employees covered by DB plans work until age 65. Stock and Wise [1990a, 1990b], Lumsdaine, Stock and Wise [1990, 1992, 1994], Gustman and Steinmeier [1989, 2000a], and Samwick [1998] present estimates of the effect of such incentives. Evidence on the early retirement effect of such incentives in public social security programs around the world is presented in Gruber and Wise [1998, 1999]. Coile and Gruber [2000] present recent estimates of such incentives in the United States Social Security program. Friedberg and Webb [2000] suggest that compared to a DB plan, a DC plan would increase the retirement age by two years. Samwick and Wise [2000] find that the average annual labor force departure rate for HRS respondents between ages 55 and 60 is 1.8 percent for persons without a pension plan, 3 percent for those with a DC plan only, 11.5 percent for persons with a DB plan only, and 12.1 percent for those with both a DB and a DC plan.

One other factor may lead our calculations to overstate the actual pension wealth Page 26 
of DB participants. Many employees do not remain under the same DB plan until the early retirement age, and thus do not accumulate the working life assets shown in the illustration above. The DB wealth at retirement would be much less if a person were to change jobs several times.

\subsection{Implications for Analyzing Pension Assets and Retirement Saving}

The illustration above highlights the difference in the age profile of asset accrual under DB and $401(\mathrm{k})$ plans, and the fact that $401(\mathrm{k})$ participants are likely to work longer than DB participants, thereby accumulating more pension assets. Thus as larger and larger numbers of employees accumulate more years of employment under DC plans, retirement plan assets relative to current earnings are likely to rise.

To link our hypothetical DB-401(k) comparison with the earlier discussion of aggregate pension assets in DB and DC plans, consider a setting in which the potential "working life" is 40 years, from ages 25 to 65 . Assume also that DC participants work the entire 40 years, but DB employees work only 30 years, until age 55 . They are retired for 10 of the 40 "working" years. Suppose that the annual DC contribution per participant is $\mathrm{C}$, and that the contribution per participant (employee) to the DB plan is $\mathrm{C} / 2$. Then over the working age 25 to 65 , contributions to the $D C$ account will be $C * 40$. But contributions per participant to the DB plan will be only $(\mathrm{C} / 2)^{\star} 30$, or only $3 / 8$ of $\mathrm{DC}$ contributions. If the DB employees work 35 years, until age 60 , DB contributions will be 43.75 percent of DB contributions. Thus, for any given cohort of workers, the accumulation of assets will depend on not only on the contribution per active (working) participant to DC and to DB 
plans, but also on the number of years over which participants work. ${ }^{12}$

The DB-401(k) illustration can also help to inform the micro comparison of the accumulation of individual pension assets under DB and 401(k) plans, as discussed below. At age 63, for example, individual (annuity) assets of DB participants are likely to be decreasing, while the assets of individual DC participants are likely still rising, as long as they are still in the labor force. Indeed survey-based estimates of DB pension wealth are often calculated by capitalizing the survey respondent's reported annuity from a DB plan. Consider, for example, the pension assets of two persons age 65 , one covered by a DB plan the other by a DC plan. Suppose the DC person just retired, while the DB person retired at age 55. Working longer will increase the assets of the DC participant. Because relatively few employees now near retirement have worked for a long period of time under a DC plan, this effect may have only a modest influence on current comparisons, like those discussed below. The effect will become quantitatively more important with the spread of $401(\mathrm{k})$ plans. Although we do not have a quantitative estimate of the magnitude of this effect, the direction seems clear.

\subsection{Empirical Evidence on DB Accruals versus Contributions}

To determine whether averaged over all ages, the increase in retirement support from DC plan saving is greater than that from DB plan saving, we can consider external data. Kotlikoff and Wise [1989] estimate that contributions to DB plans average 4 to 6 percent of the wage earnings of DB enrollees. The average $401(k)$ contribution is about

${ }^{12}$ Workers who retire earlier also get more leisure. Our focus, however, is on the accumulation of retirement assets, not on the comparison of utility of persons covered by DB and DC plans. 
9 percent of earnings. The Form 5500 data on contributions per active (working) participant above show $401(\mathrm{k})$ contributions per participant about twice as large as DB contributions per participant, and we noted above that contributions to DC plans are likely to continue over more years than contributions to DB plans. Assuming that investment returns in the two plans are similar, the $401(\mathrm{k})$ plan should provide much greater benefits at ages such as 65 for persons with similar earnings histories.

We noted above that DB plan contributions disproportionately benefit persons who are covered by the same plan over an entire working life. Employees who change jobs often will accumulate much less in DB pension assets, as documented by Kotlikoff and Wise [1989]. This conclusion is consistent with the findings of Samwick and Skinner [1998]. They compare DB and DC plans by running a broad range of earnings histories through plan provisions from the Pension Provider Supplements to the 1983 and 1995 Survey of Consumer Finances. They find that DC plans provide substantially higher retirement benefits than $\mathrm{DB}$ plans.

Form 5500 filings also provide data that matches closely the DC and DB annual saving rates (or accruals), as described algebraically above. For an individual DB plan participant, annual pension saving is the increase in promised future benefits due to working an additional year under the plan, not the contribution per participant that the firm makes to the plan. The annual accrual of promised DB benefits is reported in Form 5500 data for all plan employees combined. ${ }^{13}$ This summary statistic combines

${ }^{13}$ These data are from Schedule B of the Form 5500. Each DB plan is asked for the "expected increase in current liability due to benefits accruing in the plan year." About 25 percent of all DB plans did not file or have missing data for schedule B. The tabulations reported here are based on completed responses. 
employees of all ages, and thus may be very different from the accrual for any individual employee. Averaged over all DB plans, this accrual can be compared to the average contribution per participant in 401(k) plans.

Table 2 shows the DB change in accrued liability per active employee for 1990 through 1997, together with $401(\mathrm{k})$ contributions per participant. These data suggest that over these years the annual $401(k)$ saving rate per active (working) participant was more than twice the annual average DB saving rate. While the values reported in the Form 5500 data are imperfect--they depend on interest rate and mortality assumptions, and the response rate is low --the accrual values per employee correspond rather closely to contributions per employee in all years but 1993, when the DB contribution per employee was unusually large $(\$ 2,074)$. Thus contributions per employee, average accrued liability per employee, and the estimates of total DB versus $401(k)$ contributions as a percent of wages all seem quite consistent.

The annual accrual under DB plans is the increase in promised future benefits that the plan sponsor must fund. If the plan cannot be over- or under-funded, and there are no changes in the plan that might affect obligations to retirees, then the annual accrual puts a limit on the potential increase in plan assets. Plan contributions would fluctuate depending on the accrual and on the market return on assets held in DB plans. In contrast, there are no limits on the accumulation of assets in DC plans, although there are limits on contributions. During periods of favorable asset returns, such as the 1990s, assets of DC plans are likely to rise much more rapidly than assets in DB plans.

\section{HOUSEHOLD-LEVEL DATA ON RETIREMENT PLAN ASSET SUBSTITUTION}

Page 30 
We now turn to direct analysis of substitution between defined contribution pension assets and DB pension assets, using household data. One of the implicit assumptions in many discussions of potential substitution between DB and DC plan assets is that workers have one pension arrangement or the other. Yet in many cases, workers have both plans; we call this "dual coverage." Understanding dual coverage is essential for analyzing the potential for displacement of DB assets by $401(\mathrm{k})$ assets. We therefore begin our analysis of substitution by analyzing dual coverage, as well as other aspects of pension coverage, using the U.S. Department of Labor's Form 5500 filings. After discussion of new findings based on the Form 5500 data, we consider the potential substitution between $401(\mathrm{k}) \mathrm{s}$ assets and DB plan assets. There are several ways substitution may occur, including direct replacement of existing DB plans by 401(k)s, shrinking or capping DBs when $401(\mathrm{k}) \mathrm{s}$ are introduced to firms with existing DBs, and perhaps decisions not to introduce DB plans at firms that choose to introduce 401(k) plans instead. Engen, Gale, and Scholz [1994], Papke [1999], Engelhardt [2000], Pence [2001], and Ghilarducci [2001] discuss the different channels of substitution. We consider several ways to evaluate the possible displacement of DB plan assets by DC assets, and $401(\mathrm{k})$ assets in particular.

In considering possible displacement of plan assets, it is useful to note the trend in the number of plan participants. Figure 18 shows the proportion of wage and salary workers who are pension plan participants, including persons counted in more than one plan. The total increased from 64 to 81 percent between 1975 and 1997. Note that in 1985 and 1986, about 20 percent of the labor force participated in the IRA program. This proportion fell to about 4 percent by the mid-1990s. 


\subsection{Dual Coverage and 401(k) Plans}

Information on employer-provided pension plans, including 401(k) plans, is reported each year in firm Form 5500 filings, which provide data on funding and other financial features of pension plans. We have used these data as the basis for a number of calculations. The top panel of Table 3 shows the fraction of $401(k)$ participants that also have a DB plan for the years 1984 to 1997 . Three columns of data are presented. The first column pertains to all 401(k) plans. For the years 1988 to 1997, the second and third columns present results for pre-existing 401(k) plans and new 401(k) plans in each year. The proportion of $401(\mathrm{k})$ participants with a DB plan declined substantially over the period-from 82.4 percent to 42.4 percent. The proportion of DB participants in new 401(k) plans was substantially smaller than the proportion in existing plans, in all years. On average, the proportion in new plans was about 26 percent. There is notable year-toyear fluctuation, which we suspect is due to small sample sizes.

The second panel of Table 3 shows the $401(k)$ participation rate, given eligibility, for the years 1990 to $1997 .^{14}$ These rates are in excess of 75 percent in all years. For pre-existing plans, the rate is around 80 percent, declining from about 83 to 76 percent between 1990 and 1997. The participation rate for new plans is about 65 percent on average, with no clear trend over time. Although not shown in the table, in 1988, 86.3 percent of all plans were pre-existing and 93 percent of all participants were in preexisting plans. These proportions changed over time, so that by 1997, 95.7 percent of all

${ }^{14}$ These data are not available prior to 1990 . The participation rate is the ratio of participants with positive account balances to total participants. All other panels in this table are based on data for active (non-retired) participants. 
plans were pre-existing and 96.4 percent of participants were in these plans. Very little of the decline in DB dual coverage is accounted for by $401(\mathrm{k})$ participants with dual coverage who subsequently lost their DB plan.

Table 4 shows $401(k)$ contribution and participation rates by dual DB coverage status. The average contribution per participant increased substantially over time, as shown above. The information in Table 4 shows that the average contribution is 25 to 40 percent higher for those with than for those without a DB plan. Perhaps firms with DB plans pay higher salaries than firms without DB plans. This may make both employer and employee 401(k) contributions higher in firms offering DB plans. It is also possible, as Katona [1965] suggested, that participation in one pension plan increases workers' awareness of saving-related issues and thereby encourages other saving. Participation rates in $401(\mathrm{k})$ plans are somewhat higher for persons who have a DB plan than for those who do not. Persons with a DB plan may also be older, and PVW [1998b] show that $401(k)$ participation rates tend to increase with age.

\subsection{Loss of Dual Coverage}

The data underlying Table 3, in particular the proportion of new- and continuingplan 401(k) participants with a DB plan, are shown in the first panel of Appendix Table 1. From these data, it is possible to determine the rate at which $401(\mathrm{k})$ participants with dual coverage lose DB coverage. We find that the loss rate is 1.0 percent for $1996-97$, 4.6 percent (95-96), 1.7 percent (94-95), 0.7 percent (93-94), -1.1 percent (92-93), 6.1 percent (91-92), and -5.1 percent (90-91). A negative sign indicates that the number of 401(k) participants with DB plans increased from one year to the next. On average the year to year loss rate was 1.1 percent. 
These data show that very few persons with dual coverage lost their DB coverage over this time period. The data also show that the decline in the number of persons covered by DB plans over this period cannot be accounted for by the loss of the DB plans of 401 (k) participants; we have no reason to believe that the experience in earlier years was any different. These data suggest that the decline in the proportion of $401(\mathrm{k})$ participants with DB plans is largely accounted for by the entry of new $401(k)$ participants with low dual coverage rates. This is consistent with diffusion of $401(\mathrm{k})$ plans to smaller firms without prior DB plans.

\subsection{Hypothetical Growth of DB Assets Without 401(k) Plans}

We now consider two simple scenarios of how DB assets might have evolved in the absence of $401(\mathrm{k})$ plans. The scenarios make extreme assumptions concerning the replacement of DB plans by $401(\mathrm{k})$ plans. The results can be interpreted as providing bounds on the extent of substitution between $401(\mathrm{k})$ and DB plans. The simulations are based on three data series for the period 1984 to 1997: (1) the number of participants in 401(k) and DB plans, (2) contributions per participant to 401(k) and to DB plans, and (3) the percent of $401(\mathrm{k})$ participants that also has a DB plan. We obtain the sum of plan contributions-both to $401(\mathrm{k})$ plans and to DB plans-by persons with a 401(k) plan. We then compare this sum to contributions that would have been made to DB plans in the absence of the $401(\mathrm{k})$ program. Table 5 shows the data and calculated values.

The number of DB and $401(\mathrm{k})$ plan participants is shown in columns (2) and (3) of Table 5. The percent of $401(\mathrm{k})$ enrollees also enrolled in a DB plan is shown in column

(4). The average contribution per participant in these plans is shown in columns (5) to (8). For persons with both a DB and a $401(\mathrm{k})$, total pension saving is necessarily greater 
than saving under a stand-alone DB plan. ${ }^{15}$ In 1984, about 82 percent of $401(k)$ participants also had a DB plan. The percent of workers with dual enrollment declined rather consistently to about 42 percent in 1997. In the first years after they became available, most $401(\mathrm{k})$ plans were initiated in large firms with an already existing DB plan. Subsequently, the diffusion of $401(\mathrm{k})$ plans included larger numbers of smaller firms that were less likely to have pre-existing DB plans. To the extent that the expansion in 401(k) plans has been increasingly through plans in smaller firms without prior DB plans, 401(k) contributions are not substituting for contributions to pre-existing DB plans. Whether such firms would have adopted another plan if it were not for the 401 (k) option is an open question; we address this in the alternative scenarios below.

On average, per enrollee contributions to $401(\mathrm{k})$ plans are greater than per participant contributions to DB plans. In addition, the average DB contribution is greater for those who also have a $401(\mathrm{k})$ plan, and the $401(\mathrm{k})$ contribution is greater for those who also have a DB plan.

Contributions to the plans of employees with a $401(k)$ are shown in columns (9) to (12). We separately report DB contributions in firms with and without $401(k)$ plans, as well as contributions to $401(\mathrm{k})$ plans in firms with and without DB plans. The nominal sum of pension contributions on behalf of employees covered by a $401(\mathrm{k})$ plan over the years $1984-1997$ is $\$ 1061$ billion. About $\$ 252$ billion was contributed to the DB plans of 401(k) enrollees with dual coverage, about $\$ 499$ billion to the plans of those with dual

${ }^{15}$ DB plans generally preceded supplemental $401(\mathrm{k})$ plans. Because DB plans are formula based, it is difficult to "scale back" DB benefits when $401(\mathrm{k}) \mathrm{s}$ are introduced. Indeed, the data in Table 5 show that DB contributions are higher in firms where DB plans are supplemented by a $401(\mathrm{k})$ plan. 
coverage, and about $\$ 309$ billion to the plans of those enrolled only in a 401(k) plan.

How much higher might DB plan contributions have been in the absence of $401(\mathrm{k})$ plans? We consider two alternative scenarios that put an upper bound on the displacement of DB contributions by 401 (k) contributions. First, we assume that all persons who have stand-alone 401(k) plans would otherwise have had stand-alone DB plans in the absence of the $401(\mathrm{k})$ program. (We also assume that DB contributions for persons with both $401(\mathrm{k})$ plans and DB plans are unchanged.) As a practical matter it is unlikely that most firms that now offer only $401(\mathrm{k}) \mathrm{s}$--especially small firms--would ever offer DB plans in the absence of $401(\mathrm{k}) \mathrm{s}$, so this assumption should produce an upper bound on the amount of substitution.

Under this scenario, contributions to all DB plans would have totaled about $\$ 466$ billion from 1984 to 1997 . This is shown in column (13), which is the product of columns (3) and (7). This $\$ 466$ billion is composed of $\$ 252$ billion of actual contributions to DB plans by persons with dual coverage and $\$ 214$ billion in additional DB contributions that would result if all stand-alone $401(\mathrm{k}) \mathrm{s}$ were converted to DB plans, and if these converted plans than exhibited the average contribution rate for stand-alone DB plans. This additional $\$ 214$ billion of DB contributions represents only 26 percent of the $\$ 1,061$ billion of the total contributions to the plans of $401(k)$ participants.

The low estimate is the consequence of two factors. First, stand-alone $401(\mathrm{k})$ plans are a relatively recent phenomenon. Much of the growth of $401(\mathrm{k})$ participation, particularly in the early years, is among persons who retained DB coverage. For these persons there is little or no displacement. Second, average contribution rates to DB plans are substantially lower than contribution rates to $401(\mathrm{k})$ plans. Replacing a stand- 
alone DB plan by a stand-alone 401(k) will, on average, increase contributions per participant.

A less extreme scenario, but one that is still likely to overstate substitution, is that the entire reduction in DB plan participation between 1984 and 1997 can be attributed to displacement caused by the introduction of the $401(\mathrm{k})$ program. The number of DB participants displaced in each year under this scenario is shown in column (14). "Lost" contributions to DB plans under this scenario are shown in column (15), and they total about $\$ 86$ billion. This is only 11 percent of all $401(\mathrm{k})$ contributions.

The absence of large-scale displacement is the consequence of several factors. First, much of the growth of $401(\mathrm{k}) \mathrm{s}$, particularly in the early years, is among persons who retain their DB coverage. Second, 401(k) contributions as a share of salary are about twice as great as DB plan contributions as a share of salary, so even in the most extreme case, $401(k)$ assets could not have been fully offset by a reduction in what otherwise would have been the DB assets of the $401(\mathrm{k})$ enrollees. Indeed, the earlier discussion suggests that accumulation of retirement assets resulting from $401(\mathrm{k})$ contributions is likely to be substantially greater than the accumulation from contributions to DB plans. Finally, the decline in the number of persons covered by DB plans but not by $401(\mathrm{k})$ plans is too small to account for much of the $401(\mathrm{k})$ growth.

\subsection{Projections of 401(k) Assets}

The foregoing calculations compare aggregate $401(k)$ plan assets with aggregate DB plan assets in two hypothetical scenarios. We can also make comparisons between 401(k) assets and DB plan assets using household-level data. Data from the Health and Retirement Survey suggest that in 1992, the mean value of assets in DB plans was 
$\$ 54,800$ for persons aged 51 to 61 . The average for employees of all ages would be much less. In PVW [1998b], we estimated how much the 1992 HRS respondents would have accumulated in their $401(k)$ accounts if they had been eligible for $401(k)$ plans over their entire working lives. Based on our projections of the participation rates of future cohorts, we made forward-looking projections, one for the cohort reaching age 65 in 2025 , and the other for those reaching age 65 in 2035 . We compared our projected $401(\mathrm{k})$ assets to Social Security assets, assuming that the Social Security program remained unchanged.

We can also compare projected $401(\mathrm{k})$ assets to DB pension assets. While Social Security assets of HRS respondents averaged $\$ 103,392$, DB pension assets average only $\$ 54,500$. PVW [2001] suggests that projected 401(k) assets would be 136 to 451 percent of DB pension plan assets (depending on how contributions are invested), assuming no reduction in DB assets. Even if DB pension assets were set to zero for this cohort, which is tantamount to assuming that $401(\mathrm{k})$ plans crowded out all DB plans, there would still be substantial incremental $401(\mathrm{k})$ wealth. Data on $401(\mathrm{k})$ participation rates and contributions that have become available since we made our projections lead us to believe that, if anything, these $401(\mathrm{k})$ asset projections may underestimate future $401(\mathrm{k})$ assets.

The "cohort approach" used to obtain the projections described above has the advantage of combining all survey respondents. It is therefore not contaminated by saver heterogeneity. It is also unaffected by differences in the lifetime accumulation profiles of DB and DC assets, since the comparison is between the realized assets of persons at, or approaching, retirement. These comparisons reflect the realized assets, after a lifetime of pension saving, that are available to support retirement consumption. 


\subsection{The "Eligibility Experiment" Applied to DB Plan Assets}

In PVW [1998b], we used data from the Survey of Income and Program Participation (SIPP) to compare the financial assets and home equity of families eligible for a 401(k) with the assets of families who were not eligible. We found little difference in the assets of eligible and non-eligible families in 1984-near the introduction of the $401(\mathrm{k})$ program. By 1991, however, the assets of the eligible group were substantially greater than those of the non-eligible group. We concluded that there was essentially no substitution of $401(\mathrm{k})$ assets for other financial assets or for home equity. This comparison is the basis for our comparison of the pension assets of HRS respondents.

Following the same idea, we considered whether the apparent increase in the financial assets of the $401(\mathrm{k})$ eligible groups could have been offset by a reduction in their DB assets. For this to have happened, the DB coverage of persons who became eligible for a 401(k) plan would have had to decline. The results, however, are difficult to interpret. We now explain why, and offer our interpretation of the data patterns.

In 1984, there was little difference in the non-IRA-401(k) financial assets or the home equity assets of the eligible and ineligible groups. But, the eligible group was much more likely to have a DB plan, especially at the lower income levels, than it was in later years. By 1991, there was still little difference in the non-IRA-401(k) financial assets or the home equity assets of the two groups. But the net total financial assets of the eligible group were much greater than the financial assets of the ineligible group. There is no measure of DB plan assets for either year in the SIPP. Could the DB plan assets of the eligible group, relative to those of the ineligible group, have fallen enough to offset the increase in financial assets of the eligibles? To judge the likelihood of this, we considered 
the change in the DB coverage of the two groups.

The key DB numbers are the percent change between 1984 and 1991 in DB coverage of eligible and not eligible families. The percent decline in DB coverage was much greater for the ineligible group than for the eligible group. One might judge from this fact that there was not a disproportionate fall in the DB assets of the eligible group. But interpretation of the data is confounded by two trends. One is the general decline over time in the proportion of employees covered by a DB plan, which would affect both the eligible and the ineligible groups. The other trend is the increase in $401(\mathrm{k})$ eligibility. As 401(k) eligibility increases, families who were ineligible become eligible. The effect of this movement from ineligible to eligible status on the percent of eligibles covered by a DB plan depends on the pre-move DB coverage of the new 401(k) eligibles.

Suppose we rely on Ippolito's [2000] result that existing DB plans are very rarely terminated when $401(\mathrm{k})$ plans are started, and we accept our result above that once dual DB-401(k) coverage is established, subsequent loss in DB coverage is very unlikely. The HRS data alone do not enable us to disentangle the various determinants of DB coverage. But our attempts to match the shift in the DB coverage of the $401(\mathrm{k})$ eligible and ineligible groups suggests that during this period, most of those who moved from ineligible to eligible status had a DB before becoming eligible--reducing the proportion of the ineligible group with a DB and increasing the proportion of the eligible group with a DB plan.

\subsection{Cohort Analysis of DB vs. 401(k) Substitution}

We emphasized above that if the increase in $401(k)$ assets is to be offset by a reduction in DB assets, the reductions must come for the most part through a reduction in DB participation. We showed that the reduction over time in the DB coverage of $401(\mathrm{k})$ 
participants with dual $401(\mathrm{k})$ and DB coverage was very small, and concluded that shifting composition of the $401(\mathrm{k})$ eligible pool was the most likely explanation for changing DB participation rates of eligibles and ineligibles. Another way to evaluate the extent of the reduction in DB participation with the increase in $401(\mathrm{k})$ plans is to consider cohort data. Figure 19 shows the relationship between $401(\mathrm{k})$ eligibility and participation in DB plans for three cohorts, using data from the Survey of Income and Program Participation (SIPP) for 1984, 1987, 1991, 1993, and 1995. These data span the first 13 years of the $401(\mathrm{k})$ program. Each cohort is identified by its age in 1984. For example, the $\mathrm{C}(44)$ cohort is followed from ages 44 to 55 .

Within each cohort, there were enormous increases in $401(\mathrm{k})$ eligibility. But the within-cohort increases in $401(\mathrm{k})$ eligibility are not nearly offset by corresponding withincohort reductions in DB participation. Indeed for the two younger cohorts, both DB participation and 401(k) eligibility increase with age. There is no evidence of DB-for-401(k) offset, with rising 401(k) participation associated with declining DB plan coverage. These data pertain to all employed persons, and are not confounded by the "mixture" problem that makes the results of the eligibility experiment difficult to evaluate.

The evidence in Figure 19 does not necessarily imply that 401(k) plans did not displace any DB plans. Perhaps DB participation would have risen more rapidly were it not for the spread of $401(\mathrm{k})$ plans, or firms would have offered more generous defined benefit plans if $401(\mathrm{k}) \mathrm{s}$ had not expanded. But it seems to us extremely unlikely that DB plan participation would have increased, other things equal, as quickly as 401(k) plans spread. For example, for a cohort like the $\mathrm{C}(44)$ group, it is likely that DB participation would have changed little with age, which is what the realized data shown in the presence 
of the $401(k)$ expansion.

In addition, the 401(k) data show very large cohort effects. At any age, successively younger cohorts are much more likely to be eligible for a $401(k)$ plan. There are also DB cohort effects, with successively younger cohorts less likely, on average, to be covered by a DB plan. The data for the few cohorts shown in Figure 19, however, do-not reveal this trend. (The cohort data are only shown through age 55. The SIPP data do not allow correction for the more rapid retirement of persons covered by DB plans after the plan early retirement age, which is often 55 . Thus at older ages it is not possible to use these data to make accurate comparisons of $401(\mathrm{k})$ and DB plan participation rates.)

\section{RETIREMENT PLAN SUBSTITUTION AMONG OLDER WORKERS: HRS EVIDENCE}

The Health and Retirement Study (HRS) provides the most comprehensive information available on persons approaching retirement. The heads of households for HRS families were 51 to 61 in 1992. Some of these persons could have participated in a 401(k) plan for up to 10 years by 1992. In principle the HRS data should allow estimation

of the contribution of the $401(\mathrm{k})$ program to the saving of persons in this age group during the early years of the program. Such estimates might be obtained through a comparison of 401(k) eligibles and ineligibles, as described in the previous section and in PVW [1995]. Unfortunately, because the HRS asks respondents whether they contribute to 401(k) plan, not whether they are eligible to contribute, it is not possible to directly estimate the $401(\mathrm{k})$ eligibility effect.

In this section, we explain the problems of inferring $401(\mathrm{k})$ eligibility status in the HRS. We then discuss estimates of 401 (k) eligibility based on adjustments that at least Page 42 
partially address these problems. Finally, we use these estimates to analyze the relationship between $401(\mathrm{k})$ eligibility and pension plan assets. Consistent with the results reported above, we find no evidence that the increase in $401(k)$ assets was offset by a reduction in DB assets. We believe, however, that comprehensive determination of $401(\mathrm{k})$ eligibility status in the HRS is not possible and that our HRS results are likely to underestimate the net gain in pension retirement assets from the $401(\mathrm{k})$ program.

The relationship between 401(k) plans and DB retirement assets in the 1992 HRS is also the focus of a recent study by Engelhardt [2000]. He concludes that DB assets are higher among households ineligible for a 401(k) than among those eligible for a 401(k), suggesting substitution of $401(\mathrm{k})$ for DB pension assets. The findings presented above suggest that employees covered by $401(\mathrm{k})$ programs should have more retirement assets than employees not covered by a $401(\mathrm{k})$. We find that a key reason for the difference between Engelhardt's conclusions and ours' is the assignment of eligibility status, which is critical to determining pension wealth.

\subsection{Data Limitations in the HRS}

Our aim is to provide estimates of the pension and other assets of HRS respondents who were and were not eligible for a $401(k)$ plan. To begin, we compare DB coverage rates, for persons eligible and not eligible for a 401(k), in the HRS and in other surveys. The other surveys explicitly inquire about $401(k)$ eligibility, while the HRS does not. This comparison is presented in Table 6 and pertains to pension status on the employees' current job. ${ }^{16}$ The HRS rates are based on the assignment of eligibility used

${ }^{16}$ The HRS provides some information on pension status on prior jobs as well. We restrict attention to the current job since it is difficult to determine $401(\mathrm{k})$ eligibility on 
by Engelhardt [2000]. All entries in the table are weighted and all entries except those derived from the Form 5500 data pertain to persons in the age range covered by the HRS.

The 1992 HRS stands out as the only survey in which DB coverage is higher among $401(\mathrm{k})$ non-eligibles than among eligibles. ${ }^{17}$ In the other surveys, the DB coverage rate for eligibles is more than twice as great as the DB coverage rate for non-eligibles. The particular method used to assign eligibility is one reason for the large disparity between the HRS and other surveys. We also show below, that even under alternative, and we believe more reasonable, conventions for assigning eligibility, there remains a wide gap between the HRS DB coverage rates and the rates reported in other surveys.

The HRS does not inquire about eligibility for a $401(\mathrm{k})$, although it asks about 401(k) contributions. ${ }^{18}$ Consider the 1992 HRS data on $401(\mathrm{k})$ contributor status and DB

prior jobs. Many employees have rolled prior 401(k) balances into IRAs, and thus we are likely to underestimate $401(\mathrm{k})$ eligibility on prior jobs. The HRS percentages in the table pertain to respondents who indicated that they had a DB or $401(\mathrm{k})$ plan. We have made no attempt here to allocate other responses such as "both," "don't know," and "DC - type unknown." We have also dropped self-employed persons.

${ }^{17}$ Using households rather than persons, Engelhardt [2000] finds 51 percent of the eligibles and 48 percent of the ineligibles have a DB. A household is classified as eligible if either member is eligible for a 401(k). The data in Table 6 are also consistent with the results of Engen, Gale, and Scholz [1994] who find the ratio of eligibles with DB coverage to ineligibles with DB coverage in the SIPP to be 1.65 in 1984, 1.77 in 1987, and 2.27 in 1991.

${ }^{18}$ These are self-reported pension data. For persons who self-report having a pension, the HRS collected pension data from the employer. Thus persons who incorrectly self-report no pension coverage will be missing employer-reported data as well. In addition, the need to match every respondent to a pension combined with an employer response rate of only 65 percent means that fewer than half of the households have complete employer-reported pensions. Both Engelhardt [2000] and Gustman and Steinmeier [2000b] show an enormous degree of conflict between self-reported and firm-reported pension status. 
coverage, shown in Table 7. The HRS respondents report whether they contribute to a 401(k) and whether they are covered by a DB plan. These data are shown in the left panel of Table 8. They pertain only to persons who indicate they are included in their employer's plan. (They differ from the HRS data in Table 6, which were weighted and also include additional persons assumed to be eligible for a 401(k).) The unweighted percent of $401(k)$ contributors with a DB plan is somewhat greater than the percent of noncontributors with a DB plan--46 versus 41.7 percent. But compared to the DB coverage of 401(k) eligibles versus non-eligibles reported in other surveys (Table 6), these data for contributors versus non-contributors show a very low rate of DB coverage. Given that the HRS does not provide eligibility, we want to convert $401(\mathrm{k})$ contributor status data to 401(k) eligibility status data. In particular, to make the conversion we must identify persons among the $401(\mathrm{k})$ non-contributors who are eligible to contribute to a $401(\mathrm{k})$.

There are two separate determinations to be made. The empirically more important case involves non-contributing 401(k) eligibles who are covered by another pension. These persons would be among the 1699 persons in Table 7 who do not contribute to a 401(k), but have a DB plan. The sequence of questions in the first three waves of the HRS provides no way for a non-contributing $401(\mathrm{k})$ eligible, also covered by a DB plan, to self-identify as eligible for a 401(k); such information will be available in the 2000 wave of the HRS. Since a large portion of $401(\mathrm{k})$ eligibles are covered by a DB plan, it is likely that a large fraction of the non-contributors with a DB are in fact eligible for a 401(k).

Engelhardt [2000] assumes that all of these are non-eligibles without a DB plan, thus likely mis-classifying a large fraction of persons with a DB plan.

Here, we simply want to illustrate what the unknown eligibility numbers could be. 
Suppose we convert the contributor data to eligibility data as follows. We know from the Form 5500 data that about 82 percent of eligibles contributed to their $401(\mathrm{k})$ in 1992 . Thus there would be $1351 / .82=1648$ persons eligible for a $401(\mathrm{k})-297$ more than contributed to a 401(k). Using an extreme example, suppose that all of the 297 had a DB plan but did not contribute. Then there would be $919=622+297$ eligibles with a DB plan, and 1402 non-eligibles with a DB plan. This estimate is shown in the right panel of Table 6. The key point is that even with this assumption, only 55.8 percent of the eligible group would have a DB plan compared to 37.1 percent for the non-eligible group, a ratio of 1.5 . This ratio is still much lower than the ratios from any of the other surveys. Thus it would appear that if the data reported in the HRS are used to determine eligibility, the implied proportions of 401(k) eligibles and non-eligibles with a DB plan are far from the values in other surveys that explicitly inquire about eligibility.

There is in fact an additional problem in the HRS data, and a second determination to be made, which is not addressed in the Table 7 illustration. Respondents are asked whether they are "included" in a pension plan. Respondents who say no (and presumably do not have a DB plan), are asked whether they are eligible for a pension plan offered by their employer. About 175 respondents say yes. But we don't know what kind of pension is offered. In particular, is it a DB, $401(\mathrm{k})$, or a non-401(k) DC, or some other plan? Engelhardt [2000] assumes that all of these persons are 401(k) eligibles without a DB plan. ${ }^{19}$ Thus this assumption adds respondents with no DB coverage to the pool of $401(\mathrm{k})$

${ }^{19}$ Evidence from other surveys suggests that not all of these persons are eligible for a $401(\mathrm{k})$. The 1995 SCF asked a similar question but followed it up by asking what type of plan the respondent was eligible to be included in. Eighty percent of the weighted responses age 51-61 indicated $401(k)$ for their first job and 36 percent for their 
eligibles. Recall that the first--and more serious--mis-classification adds eligibles with DB coverage to the pool of $401(\mathrm{k})$ ineligibles. These two mis-classifications bias upward the DB assets of $401(k)$ ineligibles, and bias downward the DB assets of $401(k)$ eligibles. The combined effect of these two forms of mis-classification may be substantial.

\subsection{HRS Results Based on Eligibility}

There is no easy way to determine with certainty the $401(\mathrm{k})$ eligibility status of HRS respondents. The convention used by Engelhardt [2000], as explained above, biases downward the proportion of $401(\mathrm{k})$ eligibles with a DB plan and biases upward the proportion of $401(\mathrm{k})$ ineligibles with a DB plan. We adopt assumptions that we believe are more neutral with respect to DB coverage by $401(k)$ eligibility status.

We need to determine the eligibility of each $401(k)$ respondent. All 401(k) contributors are clearly eligible. Among 401(k) non-contributors, some are eligible and some are not. Our approach is to determine the proportion of $401(\mathrm{k})$ non-contributors that is actually eligible to contribute to a $401(\mathrm{k})$. We do this based on proportions of noncontributing eligibles that have a DB, as evident in the Form 5500 data. In 1992, 82 percent of $401(k)$ eligibles in the Form 5500 data were $401(k)$ contributors. Let $E_{E}$ be the total number of eligibles, $E_{C}$ be the number of observed contributors (all eligible), and $E_{N}$ be the number of non-contributors that should be eligible. Then the number of eligibles is

second job (62.2 percent overall). The 1993 CPS asks for the reason why a respondent is eligible, but not included. Only one-quarter of the respondents indicated that they chose not to contribute, which would suggest nonparticipation in a 401(k). Instead, parttime status and lack of tenure with the employer were the most frequently cited reasons for exclusion from an employer's pension plan. These other surveys suggest that some of cases assumed to be $401(\mathrm{k})$ eligibles in the HRS are instead persons not covered by their employer's DB plan. 
$E_{E}=E_{C}+E_{N}$. From the Form 5500 data, the ratio of contributors to eligibles is $E_{C} / E_{E}=$ 0.82 . The number of additional eligibles among the HRS non-contributors is then $E_{N}=$ $E_{C}(1 / .82-1)$. Thus, the proportion of non-contributors that should be eligible is $P=$ $(1 / 0.82-1)\left(E_{C} / N_{N}\right)$, where $N_{N}$ is the total number of non-contributors.

These calculations suggest that the percentage of non-contributors predicted to be eligible to contribute to a $401(k)$ in the HRS is equal to P percent of all observed noncontributors. Of this $\mathrm{P}$ percent, the Form 5500 data indicate that 55.7 percent have a DB plan on their current job and 44.3 percent do not. Thus we randomly reassign $.557 \times \mathrm{P}$ percent of $401(k)$ non-contributors with a DB plan in the HRS to be non-contributing eligibles. We also randomly reassign $.443 \times \mathrm{P}$ percent of $401(\mathrm{k})$ non-contributors without a DB plan to be non-contributing eligibles. This approach assures that the DB coverage rate of the respondents added to the eligibility pool is the same as the DB coverage rate of the respondents already in the pool.

Unfortunately, the Form 5500 benchmark data is not available by age or by income. The 55.7 percent dual coverage rate that we use is undoubtedly a low estimate for the HRS respondents (age 51 to 61 in 1992) because it applies to all ages, and we know from the cohort data above that older persons are more likely to have a DB plan. The other surveys also show that the percent with a DB plan increases with age.

We have adopted a similar assignment convention for missing and ambiguous responses to pension questions in the HRS. If a respondent is "included" in a pension then the respondent is asked for the plan type--DB or DC. The respondent is asked to indicate the type of pension for up to three pensions. The available choices include: "DB", "DC", or "both." A significant number of respondents did not provide a response. We use 
these conventions: (1) Respondents answering "DB" were coded as having a DB plan.

Respondents answering "DC" were then asked about the type of DC plan. The choices "thrift or saving" or " $401 \mathrm{~K} / 403 \mathrm{~B} / \mathrm{SRA}$ " or any combination involving these two choices were coded as 401(k) plans. The other choices offered pertain to non-401(k) DC plans. For respondents indicating that they have a DC plan, but did not provide the type of DC plan, we randomly assign the plan as $401(\mathrm{k})$ or not $401(\mathrm{k})$ in proportion to the number of valid responses indicating that they had 401(k) and non-401(k) DC plans. (3) Persons indicating "both" as the type of pension were coded as having a DB plan and a DC plan. For these respondents the DC plan is randomly assigned to be a 401(k) plan based on the ratio of $401(\mathrm{k}$ ) plans to all DC plans among completed responses. (4) Finally, a significant number of respondents who indicated they were included in a pension plan did not provide the type. These persons were randomly assigned as having a DB plan or a $401(\mathrm{k})$ plan in the same proportions as completed responses.

All of the calculations above are done at the level of the respondent. After these assignments are made, we combine the individual data to obtain assignments on a family basis. The asset data is reported on a family basis. A family is a $401(\mathrm{k})$ contributor, or 401(k) eligible, if either partner is a contributor, or is eligible.

Table 8 presents results comparing the assets of persons eligible and not eligible for a $401(\mathrm{k})$ plan. ${ }^{20}$ The key results are in the panel labeled "total retirement assets." Total retirement assets are substantially higher (and the difference is statistically significant for

${ }^{20}$ These are the results of weighted median regressions for 4895 households. Each household had to have at least one member working and not self-employed. Covariates include marital status and the age and education of the head. Conditional median asset balances are evaluated at the sample means of the covariates. 
all but the lowest income interval) for the $401(\mathrm{k})$ eligible group. The panel just above shows that retirement assets other than $401(\mathrm{k})$ assets do not differ much by eligibility status, except for the two highest income intervals. In these top intervals, the assets of eligibles are higher than the assets of non-eligibles. Thus these estimates suggest that the accumulation of $401(k)$ assets was not offset by a reduction in the DB assets of the HRS respondents. Non-retirement financial assets do not differ much by eligibility status. Some of the cells show zeros because fewer than half of the observations have non-zero values and thus the median is zero.

As explained above, the HRS data-even after our assignment assumptions-are likely to exaggerate the proportion of $401(\mathrm{k})$ non-eligibles with a DB plan, relative to the proportion of eligibles with a DB plan. After assignment of eligibility, the proportion of 401(k) eligibles households with DB plans is 59.3 percent and the proportion for ineligibles is 47 percent. The ratio is 1.26 , which is still much lower than the ratio reported in other surveys. The coverage percent by income interval is reported in the bottom panel of Table

8. The SIPP-based ratios reported in Table 6 exceed 2, when averaged over all income groups. Thus we believe that the calculations in Table 8 underestimate the addition to pension wealth of families eligible for a $401(k)$ plan.

\section{CONCLUSIONS}

The way Americans save for retirement has changed dramatically in the last two decades. In 1980, 92 percent of private retirement saving contributions were to employerbased plans and 64 percent of these contributions, or 59 percent of all contributions, were to DB plans. In 1999, about 85 percent of private contributions went to accounts directed 
largely by individuals. In this paper we have analyzed a broad range of aggregate and household data to understand the implications of this change.

The aggregate data show that assets in retirement plans have increased five-fold, relative to wage and salary earnings, over the past two decades. The increase in these assets to support retirement will likely mean very large increases in the assets of future retirees. The increase in $\mathrm{DC}$ assets has been so large that it is unlikely that a significant fraction of the growth in DC assets occurred at the expense of reduced DB assets.

In addition, over the past two decades, the annual retirement plan contribution rate has been over 5 percent, as a proportion of NIPA personal income, and over 8 percent relative to NIPA wage and salary earnings. Both are much higher than the NIPA personal saving rate, which is now close to zero. The treatment of retirement plan contributions and payouts in the national income accounts contributes to the very low measured personal saving rate.

Retirement saving today would likely be substantially greater if Congress had not enacted legislation in the late 1980 s to limit firm contributions to DB pension plans. In the absence of this legislation, and the favorable asset market returns during the 1990s that reduced the need for employers to contribute to their DB plans, the retirement plan contribution rate would have been at least 1 percentage point higher in the late 1990s than it actually was. It is also likely that the retirement plan contribution rate would be much higher today if it were not for the retrenchment of the IRA program after 1986.

On average, the contribution per active participant to $401(\mathrm{k})$ plans has been about twice as large as contributions to DB plans, suggesting much higher wealth accumulation under 401(k) than under DB plans. In addition, differences in the pattern of saving by age 
can have an important effect on retirement asset accumulation under the two plans. From the employee perspective, "retirement saving" through a DB or DC plan each year can be thought of as the increase in the financial support that each plan will provide in retirement. Employee retirement saving under a DC plan is quite transparent to the employee, while annual employee saving under a DB plan is quite opaque and unlikely to be clearly understood. The pattern of saving by age is much different under DB and 401 (k) plans, as we show using a hypothetical DB plan. The pattern of pension wealth accrual in the DB plan typically provides large incentive to retire early. As a consequence, DB employees will typically accumulate assets over fewer years that DC employees. Taken together, the higher contribution rate under DC plans and the greater number of years over which assets accumulate are likely to increase very substantially the asset accumulation in DC plans relative to DB plans.

Our analysis of household-level data on retirement saving yields a number of findings that complement the conclusions from the aggregate analysis. Dual coverage under both $401(\mathrm{k})$ and DB plans is common, but it has declined over time as more employees without a prior DB plan have been offered 401(k)s. Over 80 percent of 401(k) eligibles had a DB plan in 1984 and about 43 percent had one in 1997. Few 401(k) participants covered by a DB plan--only about one percent each year--subsequently lose DB coverage. Our estimates suggest that between 1984 and 1997, total contributions to all pension plans of persons with a 401(k) plan were three times as great as what contributions to defined benefit plans would have been in the absence of the $401(k)$ program. The displacement of DB plan contributions was probably less than 11 percent of the total plan contributions of $401(\mathrm{k})$ participants. 
Based on our prior independent projections, the mean 401(k) balances of persons who will reach retirement age in 2035 will be 1.4 to 4.5 times as great, depending on asset market returns, as mean DB balances, assuming no decline in DB coverage. Cohort analysis shows a decline in DB coverage for successively younger cohorts, but no withincohort reduction in DB coverage as $401(\mathrm{k})$ coverage increased.

The HRS data suggest that accumulation of $401(\mathrm{k})$ assets substantially increased the total retirement assets of persons approaching retirement in 1992. We find no evidence of substitution of $401(k)$ assets for DB assets for persons in the HRS age group. 


\section{REFERENCES}

Benjamin, Daniel J., "Does 401(k) Eligibility Increase Savings?,” mimeo, October 2000.

Bernheim, B. Douglas and John Shoven. "Pension Funding and Saving." In Z. Bodie, J. Shoven, and D. Wise, eds., Pensions in the U.S. Economy, Chicago: University of Chicago Press, 1988, 85-111.

Burtless, Gary and Joseph F. Quinn. "Retirement Trends and Policies to Encourage Work Among Older Americans," mimeo, Boston College, 2000.

Coile, Courtney and Jonathan Gruber. "Social Security and Retirement." NBER Working Paper No. 7830, 2000.

Engelhardt, Gary, "Have 401(k)s Raised Household Saving? Evidence from the Health and Retirement Survey," mimeo, Syracuse University, 2000.

Engen, Eric and William Gale. "The Effects of 401(k) Plans on Household Wealth: Differences Across Earnings Groups," mimeo, Federal Reserve Board of Governors, 2000.

Engen, Eric, William Gale and John Karl Scholz. "Do Saving Incentives Work?” Brookings Papers on Economic Activity. Vol. 1. 1994. P. 85-179.

Friedberg, Leora and Anthony Webb. "The Impact of 401(k) Plans on Retirement." University of California, San Diego Discussion Paper 2000-30, November 2000.

Gale, William, and John Sabelhaus. "Perspectives on the Household Saving Rate." Brookings Papers on Economic Activity 1999:1, 181-224.

Gruber, Jonathan and David A. Wise. "Social Security and Retirement: An International Perspective," American Economic Review, Papers and Proceedings, 1998. - Social Security and Retirement Around the World, University of 
Chicago Press, 1999.

Gustman, Alan and Thomas Steinmeier, "An Analysis of Pension Benefit Formulas,

Pension Wealth, and Incentives From Pensions." Research in Labor Economics, vol. 10, 1989, p. 53-106.

. "The Stampede Towards Defined Contribution Plans: Fact or

Fiction?", Industrial Relations, vol. 31 no. 2, Spring 1992, 361-369.

. "Employer Provided Pension Data in the NLS Mature Women's

Survey and in the Health and Retirement Study," in Solomon Polachek (ed.),

Worker Well-Being, Elsevier Science, NY, 2000a, p. 215-252.

. "What People Don't Know About Their Pensions and Social

Security: An Analysis Using Linked Data From the Health and Retirement Study," Mimeograph, Dartmouth College, 2000b.

Ippolito, Richard, "Toward Explaining the Growth of Defined Contribution Plans," Industrial Relations, vol. 34 no. 1, January 1995, p. 1-19.

Ippolito, Richard, "Reversion Taxes, Contingent Benefits, and the Decline in Pension Funding," Journal of Law and Economics, 44 (April 2001).

Ippolito, Richard A. and John Thompson, "The Survival Rate of Defined Benefit Pension Plans, 1987-1995," Industrial Relations 39 (April 2000), 228-245.

Kotlikoff, Laurence J. and David A. Wise. "The Incentive Effect of Private Pension Plans," in Zvi Bodie, John Shoven, and David A. Wise (eds.) Issues in Pension Economics, University of Chicago Press, 1987.

. "Pension Backloading, Wage Taxes, and Work Disincentives," in L.

Summers (ed.) Tax Policy and the Economy, Vol. 2, MIT Press, 1988. 
. "Employee Retirement and a Firm's Pension Plan," in David A.

Wise (ed.) Economics of Aging, University of Chicago Press, 1989a. . The Wage Carrot and the Pension Stick, W.E. Upjohn Institute for

Employment Research, 1989b.

Katona, George, Private Pensions and Individual Saving, Ann Arbor: Institute for Social Research, University of Michigan, 1965.

Lazear, Edward. "Incentive Effects of Pensions," in D. A. Wise, ed., Pensions, Labor, and Individual Choice (Chicago: University of Chicago Press, 1985), 253-282.

LeBlanc, Pierre. "The Tradeoff Between Pensions and RRSP Contributions." Working Paper. October 2001.

Lumsdaine, Robin L., James H. Stock, and David A. Wise. "Efficient Windows and Labor Force Reduction," Journal of Public Economics 43, 1990: 131-159.

. "Three Models of Retirement: Computational Complexity Versus

Predictive Validity," in David A. Wise (ed.), Topics in the Economics of Aging, University of Chicago Press, 1992.

. "Pension Plan Provisions and Retirement: Men \& Women,

Medicare, and Models," in David A. Wise (ed.) Studies in the Economics of Aging, University of Chicago Press, 1994.

. "Retirement Incentives: The Interaction Between Employer-

Provided Pension Plans, Social Security, and Retiree Health Benefits," in M. Hurd and N. Yashiro,(eds.), The Economic Effects of Aging in the United States and Japan, University of Chicago Press, 1997.

Lusardi, Annamarie, Jonathan Skinner, and Steven Venti. "Saving Puzzles and Saving Page 56 
Policies in the United States," Oxford Review of Economic Policy, vol. 17 no. 1, (Spring 2001), 95-115.

Papke, Leslie. "Are 401(k) Plans Replacing Other Employer-Provided Pensions?

Evidence from Panel Data," Journal of Human Resources 34 (1999), 346-368.

Papke, Leslie, Mitchell Petersen, and James Poterba, "Do 401(k) Plans Replace Other

Employer Provided Pensions?," in D. Wise, ed., Advances in the Economics of Aging, Chicago: University of Chicago Press, 1996, 219-236.

Pence, Karen, "401(k)s and Household Saving: New Evidence from the Survey of Consumer Finances," mimeo, Federal Reserve Board of Governors, September 2001.

Poterba, James M. and Steven F. Venti, and David A. Wise. "Do 401(k) Contributions Crowd Out Other Private Saving?" Journal of Public Economics 58 (1995), $1-32$.

. "How Retirement Saving Programs Increase Saving," Journal of

Economic Perspectives, Fall 1996.

. "Personal Retirement Savings Programs and Asset Accumulation:

Reconciling the Evidence," in D. Wise, ed., Frontiers in the Economics of Aging, University of Chicago Press, 1998a.

. "Implications of Rising Personal Retirement Saving," in D. Wise, ed., Frontiers in the Economics of Aging, University of Chicago Press, 1998b. . "Pre-retirement Cashouts and Foregone Retirement Saving:

Implications for 401(k) Asset Accumulation," forthcoming in D. Wise, ed., Themes in the Economics of Aging, University of Chicago Press, forthcoming 2001. 
Reinsdorf, Marshall and Maria Perozek. "Alternative Measures of Personal Saving and Measures of Change in Personal Wealth," mimeo, Federal Reserve Board of Governors, 2000.

Samwick, Andrew, "New Evidence on Pensions, Social Security, and the Timing of Retirement," Journal of Public Economics, vol. 70, Nov. 1998, p. 207-236.

Samwick, Andrew and Jonathan Skinner, "How Will Defined Contribution Pension Plans Affect Retirement Income?," NBER Working Paper 6645, July 1998.

Samwick, Andrew and David A. Wise, "Pension Benefits and Retirement: Using HRS Data," Working Paper, March 2001.

Schieber, Sylvester and John Shoven. "The Consequences of Population Aging on Private Pension Fund Saving and Asset Markets," in Michael Hurd and Naohiro Yashiro, eds., The Economic Effects of Aging in the United States and Japan. Chicago: University of Chicago Press, 1997, 111-130.

Stock, James H. and David A. Wise, "Pensions, the Option Value of Work, and Retirement," Econometrica 58, 5, September 1990a: 1151-1180. . "The Pension Inducement to Retire: An Option Value Analysis," in David A. Wise (ed.), Issues in the Economics of Aging, University of Chicago Press, $1990 b$.

U.S. Department of Labor, Private Pension Plan Bulletin: Abstract of 1996 Form 5500 Annual Reports. Washington: Pension and Welfare Benefits Administration, Number 9, Winter 1999-2000. 


\section{Appendix 1: Data Sources}

Figure 1. Private retirement assets are the sum of DB, DC pension reserves from the Flow of Funds Accounts (FFA) and IRA assets from Sabelhaus (2000). Total retirement assets also include state, local and federal pension reserves from the FFA. Wage and salary disbursements are from Table 2.1 of the NIPA. Pension assets held by life insurance companies are excluded.

Figure 2. DB and DC assets for 1985-99 are from the FFA. For the years 1975-1984 estimates are obtained by applying the ratio of DB to DC assets from Form 5500 filings to total assets from the FFA. IRA assets are from Sabelhaus (2000). The figure excludes private pension assets held by life insurance companies.

Figure 3. All series from the FFA.

Figure 4. Housing equity if rom the FFA. Other assets are total net worth (from the FFA) less housing equity less private retirement assets as defined in note to figure 1a. Personal disposable income from Table 2.1 of the NIPA.

Figure 5a. DB and DC contributions are from Form 5500 reports. The data for 1998 and 1999 are authors estimates. IRA and Keogh contributions are from the IRS Statistics of Income. The IRA contributions pertain to tax-deductible contributions only.

Figure $5 \mathrm{~b}$. Private pension contributions are the sum of the components described in figure 5a. State and local and federal contributions are from the NIPA.

Figure 6a. Private pension contributions are the sum of the components described in figure 5a. Total pension contributions are the sum of the components described in Figure 5b. Personal disposable income is from NIPA. 
Figure 6b. Private pension contributions are the sum of the components described in figure 5a. Total pension contributions are the sum of the components described in Figure 5b. Wage and salary earnings (disbursements) are from the NIPA.

Figure 7,8a. All series except IRA and Keogh participants are from the Form 5500. IRA and Keogh participants are from SOI. 401(k) data for 1982, 1983 are authors' estimates. Figure 8b. The 401(k) series is from the Form 5500. 401(k) data for 1982 and 1983 are authors' estimates. The IRA data are from the IRS Statistics of Income.

Figure 8c. The Keogh data are from the IRS Statistics of Income.

Figures $9,10,11$. All DB and DC plan data are from the Form 5500, while Keogh data are from the IRS Statistics of Income.

Figure 12. Actual pension contributions are the same as in Figure 6b. The DB adjusted series is as described in the text. Data to calculate this series are not available after 1996. Wage and salary earnings (disbursements) are from the NIPA.

Figure 13. All data are from the form 5500.

Figure 14. IRA contributions are from the IRS Statistics of Income. The IRA contributions pertain to tax-deductible contributions only. IRA benefits are from Sabelhaus (2000).

Figures 15-17. Authors' calculations as described in the text.

Figure 18. DB, DC, and 401(k) participants are from the Form 5500. IRA and Keogh participants are from the IRS Statistics of Income. Wage and Salary employment from the DOL web page.

Figure 19. Authors' calculations from the SIPP. 


\section{Appendix: The DB Loss Ratio from Dual Coverage Participants}

The first panel of Appendix Table A-1 shows the raw data, calculated from Form 5500 filings, that we use to estimate the DB loss ratio. The second panel (third column) determines the additions to existing plans. The number of additional participants to new plans from years $t$ to $t+1$ is simply the increase in total participants, less the participants in plans just started that year. The identity governing its evolution is:

Number in $401(k)$ with a DB in year $\mathrm{t}+1=$ Number in $401(\mathrm{k})$ with a DB in year $\mathrm{t}+$ Number in new $401(k)$ with a DB in year $t+1+$ [(Number in $401(k)$ with DB in $t)+($ DB coverage additions to existing $401(k) s)]^{*}(D B$ loss rate $)$ The DB loss rate is the proportion of persons with a DB who drop (or lose) the DB plan. We assume that among the additional participants in existing $401(\mathrm{k})$ plans, the percent with a DB plan is the same as the percent with a DB in existing plans in the prior year. The components of the loss ratio calculations are shown in the last section of the table. DB denotes the number of workers with DB plans, $\mathrm{N}$ denotes the number in existing plans, $P$ the proportion in existing $401(k)$ plans with a DB plan, $n$ the number of workers in new plans, $p$ the proportion in new plans with a DB plan,A the number of additions to participants in existing plans, $\mathrm{P}$ the proportion of additions with a $\mathrm{DB}, \mathrm{I}$ the proportion of those with a DB who drop the plan, and t the year. The formula for the loss ratio is then:

$$
\begin{aligned}
D B_{t+1} & =\left(N_{t} P_{t}+n_{t} p_{t}+n_{t+1} p_{t+1}\right)+\left(N_{t} P_{t}+n_{t} p_{t}+A_{t+1} P_{t}\right) l \\
l & =\frac{D B_{t+1}-\left(N_{t} P_{t}+n_{t} p_{t}+n_{t+1} p_{t 1}\right)}{\left(N_{t} P_{t}+n_{t} p_{t}+A_{t+1} P_{t}\right)}
\end{aligned}
$$




\begin{tabular}{|c|c|c|c|c|c|c|c|c|c|}
\hline \multicolumn{10}{|c|}{ Appendix Table 1. Calculation DB Plan Loss Ratio } \\
\hline \multirow{3}{*}{ Year } & \multirow{2}{*}{\multicolumn{4}{|c|}{$\begin{array}{l}\text { From Form } \mathbf{5 5 0 0} \text { Filings } \\
\text { Plans in 1st year }\end{array}$}} & \multirow{2}{*}{\multicolumn{2}{|c|}{ Pre-existing plans }} & \multicolumn{3}{|c|}{ Additions to Existing Plans } \\
\hline & & & & & & & \multirow{2}{*}{$\begin{array}{l}\text { Participant } \\
\text { Increase All } \\
\text { Plans }\end{array}$} & \multirow{2}{*}{$\begin{array}{l}\text { Participants } \\
\text { From } \\
\text { New Plans }\end{array}$} & \multirow{2}{*}{$\begin{array}{l}\text { Additions to } \\
\text { Existing Plans }\end{array}$} \\
\hline & $\begin{array}{c}\text { active } \\
\text { participants }\end{array}$ & $\begin{array}{l}\% \text { with } \\
\text { DB plan }\end{array}$ & $\begin{array}{c}\text { active } \\
\text { participants }\end{array}$ & $\begin{array}{c}\% \text { with } \\
\text { DB plan }\end{array}$ & $\begin{array}{c}\text { active } \\
\text { participants }\end{array}$ & $\begin{array}{l}\% \text { with } \\
\text { DB plan }\end{array}$ & & & \\
\hline 1990 & $\begin{array}{c}T \\
T \\
20365592\end{array}$ & $\begin{array}{c}\mathrm{t} \\
61.8\end{array}$ & $\begin{array}{c}\mathrm{n} \\
1113387\end{array}$ & $\begin{array}{c}\mathrm{p} \\
32.8\end{array}$ & $\underset{19252205}{N}$ & $\begin{array}{c}P \\
63.5\end{array}$ & $T(t+1)-T(t)$ & & $T(t)+n(t+1)-T(t+1)$ \\
\hline 1991 & 21129557 & 58.2 & 1237212 & 26.1 & 19892345 & 60.2 & 763965 & 1237212 & -473247 \\
\hline 1992 & 24064248 & 55.7 & 1587113 & 19.0 & 22477135 & 58.3 & 2934691 & 1587113 & 1347578 \\
\hline 1993 & 25576318 & 52.9 & 1232422 & 22.9 & 24343896 & 54.4 & 1512070 & 1232422 & 279648 \\
\hline 1994 & 27241793 & 51.0 & 817009 & 32.9 & 26424784 & 51.6 & 1665475 & 817009 & 848466 \\
\hline 1995 & 30803020 & 46.9 & 1028994 & 28.0 & 29774026 & 47.6 & 3561227 & 1028994 & 2532233 \\
\hline 1996 & 33854427 & 45.8 & 873167 & 39.4 & 32981260 & 46.0 & 3051407 & 873167 & 2178240 \\
\hline \multirow[t]{5}{*}{1997} & 37716368 & 42.4 & 1377491 & 22.5 & 36338877 & 43.2 & $\begin{array}{c}3861941 \\
17,350,776\end{array}$ & $\begin{array}{c}1377491 \\
\mathbf{8}, \mathbf{1 5 3 , 4 0 8}\end{array}$ & $\begin{array}{c}2484450 \\
9,197,368\end{array}$ \\
\hline & \multicolumn{9}{|c|}{ Determination of Loss Ratio } \\
\hline & Exist Plans & New Plans & & Additions & & Additions with & Loss & Participants & \\
\hline & with DB & with DB & & & & DB & Ratio & losing & \\
\hline & $\begin{array}{c}\text { NP } \\
12229001\end{array}$ & $\begin{array}{c}\mathrm{np} \\
365080\end{array}$ & $\begin{array}{c}N P+n p \\
12594080\end{array}$ & $A(t+1)$ & $\mathrm{DB}(\mathrm{t}+1)$ & $A(t+1) P(t)$ & I & DB plans & \\
\hline 1991 & 11973202 & 322912 & 12296115 & -473247 & 12295289 & -300606 & -0.051 & -612973 & \\
\hline 1992 & 13099674 & 301075 & 13400750 & 1347578 & 13401380 & 811107 & 0.061 & 837105 & \\
\hline 1993 & 13245514 & 282225 & 13527738 & 279648 & 13527315 & 162979 & -0.011 & -156999 & \\
\hline 1994 & 13629904 & 268551 & 13898454 & 848466 & 13898763 & 461650 & 0.007 & 105307 & \\
\hline 1995 & 14160527 & 287604 & 14448131 & 2532233 & 14446616 & 1306126 & 0.017 & 281570 & \\
\hline 1996 & 15164783 & 344202 & 15508986 & 2178240 & 15508713 & 1035971 & 0.046 & 769228 & \\
\hline 1997 & 15680225 & 309935 & 15990161 & 2484450 & 15987968 & $\begin{array}{c}1142350 \\
\mathbf{4 , 6 1 9 , 5 7 7} \\
\end{array}$ & 0.010 & $\begin{array}{c}182672 \\
1,405,910\end{array}$ & \\
\hline
\end{tabular}




\begin{tabular}{|c|c|c|c|c|c|c|c|c|c|}
\hline \multirow{3}{*}{$\begin{array}{c}(1) \\
\text { Age }\end{array}$} & (2) & (3) & (4) & (5) & (6) & (7) & (8) & (9) & (10) \\
\hline & \multirow[t]{2}{*}{ Wage } & \multicolumn{2}{|c|}{ Saving / Wage } & \multicolumn{2}{|c|}{ Saving in Dollars } & \multicolumn{4}{|c|}{$\begin{array}{l}\text { Saving as Increment to Wealth at } \\
\text { Retirement }\end{array}$} \\
\hline & & DB & 401(k) & $\mathrm{DB}$ & $401(k)$ & $\mathrm{DB}$ & $\begin{array}{l}401(\mathrm{k}) \\
\text { To } 65\end{array}$ & $\begin{array}{l}401(k) \\
\text { To } 55\end{array}$ & $\begin{array}{l}401(k) \\
\text { To } 60\end{array}$ \\
\hline 25 & 9229 & 0 & 0.09 & 0 & 831 & 0 & 26089 & 11020 & 16956 \\
\hline 29 & 11991 & 0.053 & 0.09 & 636 & 1079 & 5973 & 24012 & 10143 & 15606 \\
\hline 30 & 12754 & 0.016 & 0.09 & 207 & 1148 & 1640 & 23433 & 9898 & 15230 \\
\hline 35 & 16983 & 0.029 & 0.09 & 494 & 1528 & 2539 & 20279 & 8566 & 13180 \\
\hline 40 & 21784 & 0.049 & 0.09 & 1063 & 1961 & 3552 & 16906 & 7141 & 10988 \\
\hline 45 & 26908 & 0.078 & 0.09 & 2097 & 2422 & 4554 & 13572 & 5733 & 8821 \\
\hline 50 & 31998 & 0.119 & 0.09 & 3809 & 2880 & 5376 & 10490 & 4431 & 6818 \\
\hline 54 & 35757 & 0.162 & 0.09 & 5782 & 3218 & 5782 & 8304 & 3508 & 5397 \\
\hline 55 & 36623 & -0.046 & 0.09 & -1672 & 3296 & -1672 & 7803 & 3296 & 5071 \\
\hline 60 & 40330 & -0.118 & 0.09 & -4765 & 3630 & -4765 & 5585 & -- & 3630 \\
\hline 64 & 42363 & -0.189 & 0.09 & -8016 & 3813 & -8016 & 4156 & -- & -- \\
\hline \multicolumn{2}{|r|}{64} & 0.017 & 0.09 & 111 & 2425 & -- & 14768 & -- & -- \\
\hline \multicolumn{2}{|c|}{$\begin{array}{l}\text { Average, } \\
\text { ages 25-54 }\end{array}$} & 0.062 & 0.09 & 1730 & 2025 & 3549 & -- & 7535 & -- \\
\hline \\
\hline & 55 & & \multicolumn{6}{|c|}{$\begin{array}{l}\text { retire at age: } \\
55\end{array}$} & \\
\hline & 60 & & & & & 142139 & -- & -- & 362205 \\
\hline & 65 & & & & & 181458 & 575970 & -- & -- \\
\hline
\end{tabular}


Table 2. Change in DB Plan Annual Accrued Liability per Active Employee, and 401 (k) Plan Contribution per Participant.

\begin{tabular}{lccc} 
Year & $\begin{array}{c}\text { DB Change in Accrued } \\
\text { Liability per Active } \\
\text { Employee }\end{array}$ & $\begin{array}{c}401(\mathrm{k}) \\
\text { Contribution } \\
\text { per } \\
\text { Participant }\end{array}$ & $\begin{array}{c}\text { Ratio } \\
401(\mathrm{k}) \text { to DB } \\
\text { Saving }\end{array}$ \\
1990 & 961 & 2507 & 2.61 \\
1991 & 976 & 2694 & 2.76 \\
1992 & 1110 & 2872 & 2.59 \\
1993 & 1252 & 2996 & 2.39 \\
1994 & 1315 & 3010 & 2.29 \\
1995 & 1359 & 3115 & 2.29 \\
1996 & -- & 3371 & 1.69 \\
1997 & 1784 & 3065 & 1.72 \\
\multicolumn{4}{|c}{} \\
data are authors' calculations from Form 5500 data. To eliminate apparent \\
errors, plans with change in accrued liability greater than \$10,000 per \\
have been deleted. Essentially the same results are obtained if plans with a \\
reater than \$20,000 per employee are eliminated.
\end{tabular}




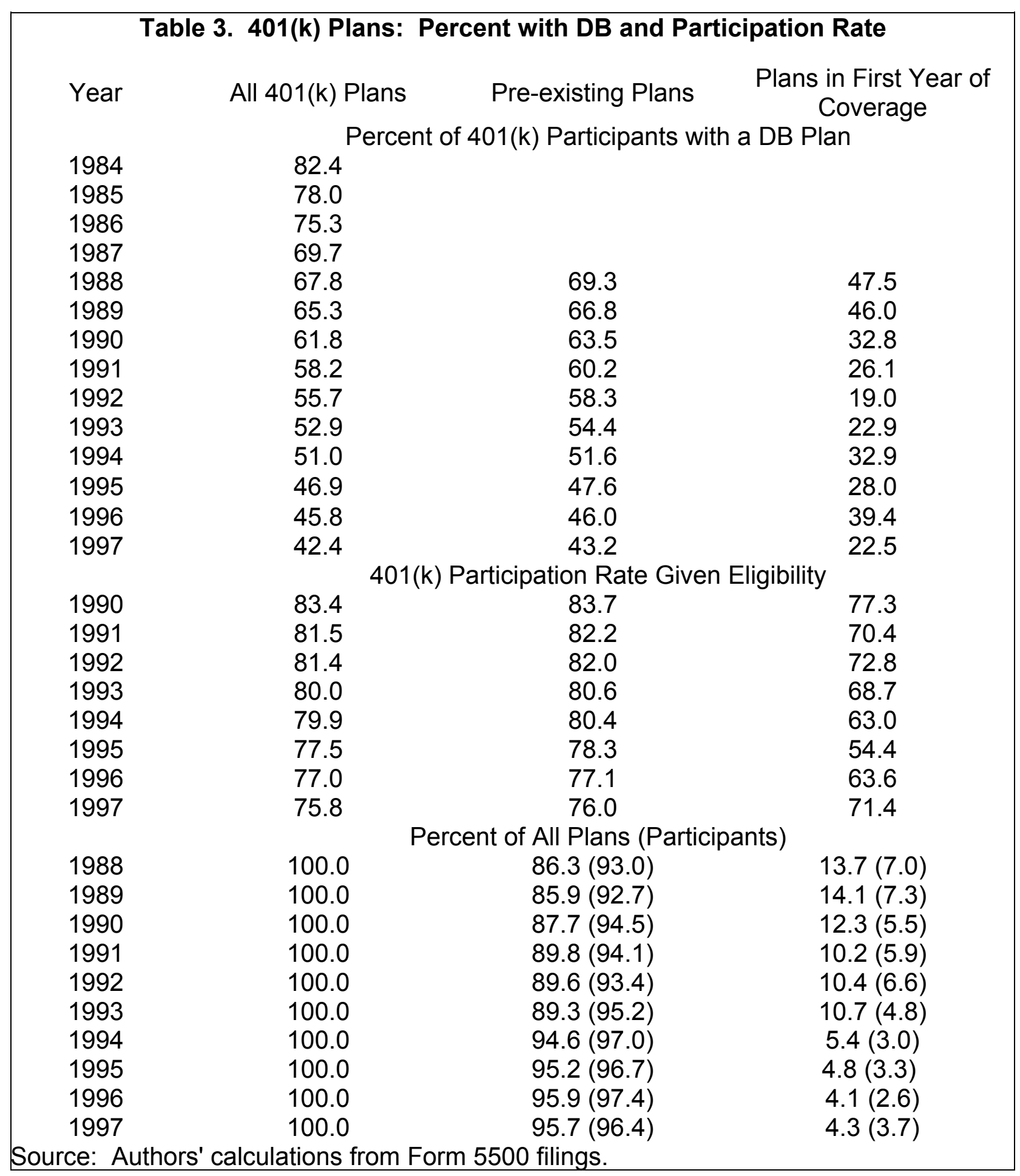




\begin{tabular}{|c|c|c|c|}
\hline & All $401 \mathrm{k}$ plans & With a DB plan & Without a DB Plan \\
\hline & \multicolumn{3}{|c|}{ Contributions per Active Participant } \\
\hline 1990 & 2394 & 2586 & 2082 \\
\hline 1991 & 2433 & 2700 & 2061 \\
\hline 1992 & 2594 & 2916 & 2188 \\
\hline 1993 & 2718 & 3075 & 2310 \\
\hline 1994 & 2744 & 3154 & 2315 \\
\hline 1995 & 2896 & 3417 & 2435 \\
\hline 1996 & 3001 & 3429 & 2638 \\
\hline \multirow[t]{2}{*}{1997} & 3056 & 3615 & 2645 \\
\hline & \multicolumn{3}{|c|}{ Participation Rate Given Eligible } \\
\hline 1990 & 83.4 & 83.4 & 83.3 \\
\hline 1991 & 81.5 & 83.3 & 79.0 \\
\hline 1992 & 81.4 & 83.9 & 78.2 \\
\hline 1993 & 80.0 & 82.4 & 77.3 \\
\hline 1994 & 79.9 & 82.3 & 77.3 \\
\hline 1995 & 77.5 & 80.4 & 74.9 \\
\hline 1996 & 77.0 & 80.5 & 74.1 \\
\hline 1997 & 75.8 & 78.4 & 74.0 \\
\hline
\end{tabular}




\begin{tabular}{|c|c|c|c|c|c|c|c|}
\hline \multicolumn{8}{|c|}{ Table 5. Contributions of Current 401(k) Participants With \& Without 401(k) Program } \\
\hline \multirow[b]{2}{*}{ Year } & \multirow{2}{*}{$\begin{array}{l}\text { DB } \\
\text { Partici- } \\
\text { pants }\end{array}$} & \multirow{2}{*}{$\begin{array}{c}\text { Partici- } \\
\text { pants }\end{array}$} & \multirow{2}{*}{$\begin{array}{l}\% \text { with } \\
\text { DB Plan }\end{array}$} & \multicolumn{2}{|c|}{ DB Contribution } & \multicolumn{2}{|c|}{ 401(k) Contribution } \\
\hline & & & & $\begin{array}{l}\text { Without } \\
401(k)\end{array}$ & With 401(k) & Without DB & With DB \\
\hline (1) & (2) & (3) & (4) & (5) & (6) & (7) & (8) \\
\hline 1984 & 30172 & 7579 & 0.824 & 1332 & 1640 & 2202 & 2411 \\
\hline 1985 & 29024 & 10352 & 0.78 & 1350 & 1350 & 1866 & 2605 \\
\hline 1986 & 28670 & 11573 & 0.753 & 1516 & 1382 & 2194 & 2841 \\
\hline 1987 & 28432 & 13163 & 0.697 & 1287 & 1250 & 2312 & 2796 \\
\hline 1988 & 28081 & 15424 & 0.678 & 1481 & 1279 & 2148 & 2775 \\
\hline 1989 & 27304 & 18449 & 0.653 & 1385 & 1067 & 2176 & 2728 \\
\hline 1990 & 26344 & 20366 & 0.618 & 1143 & 695 & 2082 & 2586 \\
\hline 1991 & 25747 & 21130 & 0.582 & 1270 & 1018 & 2061 & 2700 \\
\hline 1992 & 25362 & 24064 & 0.557 & 1355 & 1338 & 2188 & 2916 \\
\hline 1993 & 25127 & 25576 & 0.529 & 1538 & 2333 & 2310 & 3075 \\
\hline 1994 & 24615 & 27242 & 0.51 & 1576 & 1540 & 2315 & 3154 \\
\hline 1995 & 23531 & 30803 & 0.469 & 1809 & 2094 & 2435 & 3417 \\
\hline 1996 & 23262 & 33854 & 0.458 & 1886 & 1484 & 2638 & 3429 \\
\hline \multirow[t]{5}{*}{1997} & 22866 & 37716 & 0.424 & 1979 & 2247 & 2645 & 3615 \\
\hline & \multicolumn{4}{|c|}{ Persons with a $401(\mathrm{k})$} & $\begin{array}{l}\text { tributions } \\
\text { If all 401(k) } \\
\text { Participants }\end{array}$ & \multicolumn{2}{|c|}{$\begin{array}{c}\text { DB Displacement }=\text { Decline } \\
\text { in DB Plans }\end{array}$} \\
\hline & \multicolumn{2}{|c|}{ With a DB Plan } & Without a & Total & Had a DB & $\mathrm{DB}$ & Lost DB \\
\hline & DB & $401(k)$ & & & & $\begin{array}{l}\text { Participants } \\
\text { Displaced }\end{array}$ & \\
\hline & (9) & (10) & (11) & (12) & (13) & (14) & (15) \\
\hline 1984 & 10242 & 15057 & 2937 & 28236 & 10095 & 0 & 0 \\
\hline 1985 & 10901 & 21034 & 4250 & 36185 & 13975 & 1148 & 1550 \\
\hline 1986 & 12043 & 24758 & 6272 & 43073 & 17545 & 1502 & 2277 \\
\hline 1987 & 11468 & 25652 & 9221 & 46341 & 16941 & 1740 & 2239 \\
\hline 1988 & 13375 & 29019 & 10668 & 53062 & 22843 & 2091 & 3097 \\
\hline 1989 & 12854 & 32865 & 13930 & 59649 & 25552 & 2868 & 3972 \\
\hline 1990 & 8747 & 32548 & 16198 & 57493 & 23278 & 3828 & 4375 \\
\hline 1991 & 12519 & 33204 & 18203 & 63926 & 26835 & 4425 & 5620 \\
\hline 1992 & 17934 & 39085 & 23325 & 80344 & 32607 & 4810 & 6518 \\
\hline 1993 & 31565 & 41604 & 27827 & 100996 & 39336 & 5045 & 7759 \\
\hline 1994 & 21396 & 43820 & 30902 & 96118 & 42933 & 5557 & 8758 \\
\hline 1995 & 30251 & 49364 & 39828 & 119443 & 55723 & 6641 & 12014 \\
\hline 1996 & 23010 & 53167 & 48404 & 124581 & 63849 & 6910 & 13032 \\
\hline 1997 & 35933 & 57810 & 57461 & 151204 & 74640 & 7306 & 14459 \\
\hline Total & 252238 & 498987 & 309426 & 1060651 & 466152 & 53871 & 85669 \\
\hline
\end{tabular}




\begin{tabular}{|lccc|}
\hline \multicolumn{4}{|c|}{ Table 6. Percent of 401 (k) Eligibles and Ineligibles with a DB Pension, by Survey } \\
Survey and Year & Eligibles & Ineligibles & Ratio \\
1992 HRS & 40.8 & 43.6 & 0.94 \\
Form 5500 & 55.7 & - & \\
1993 CPS & 53.9 & 25.4 & 2.12 \\
1991 SIPP & 69.5 & 28.4 & 2.45 \\
1995 SCF & 38.3 & 17.2 & 2.23 \\
\hline
\end{tabular}

\begin{tabular}{|c|c|c|c|c|c|c|}
\hline & & & Eligib & & & \\
\hline DB & $\operatorname{Re}$ & rted in the & HRS & Inferred & m Exter & Sources \\
\hline Coverage & & (k) Contri & utor & & 1(k) Eligi & \\
\hline & Yes & No & All & Yes & No & \\
\hline Number: & & & & & & \\
\hline DB & 622 & 1699 & 2321 & 919 & 1402 & 2321 \\
\hline No DB & 729 & 2376 & 3105 & 729 & 2376 & 3105 \\
\hline All & 1351 & 4075 & 5426 & 1648 & 3778 & 5426 \\
\hline Percent: & & & & & & \\
\hline DB & $46.0 \%$ & $41.7 \%$ & $42.8 \%$ & $55.8 \%$ & $37.1 \%$ & $42.8 \%$ \\
\hline No DB & $54.0 \%$ & $58.3 \%$ & $57.2 \%$ & $44.2 \%$ & $62.9 \%$ & $57.2 \%$ \\
\hline All & $100.0 \%$ & $100.0 \%$ & $100.0 \%$ & $100.0 \%$ & $100.0 \%$ & $100.0 \%$ \\
\hline
\end{tabular}




\begin{tabular}{|c|c|c|c|c|c|c|}
\hline \multirow{2}{*}{$\begin{array}{l}\text { Asset Category } \\
\text { and Eligibility } \\
\text { Status }\end{array}$} & \multicolumn{6}{|c|}{ Income Interval } \\
\hline & $<\$ 20,000$ & $\begin{array}{l}20,000- \\
30,000\end{array}$ & $\begin{array}{l}30,000- \\
40,000\end{array}$ & $\begin{array}{c}40,000- \\
50,000\end{array}$ & $\begin{array}{l}50,000- \\
75,000\end{array}$ & $>75,000$ \\
\hline \multicolumn{7}{|c|}{ Net Non-Retirement Financial Assets } \\
\hline Eligible & 3069 & 3862 & 5614 & 8983 & 14672 & 33155 \\
\hline Ineligible & 2897 & 3069 & 6310 & 6250 & 13966 & 23690 \\
\hline Difference & 172 & 793 & -697 & 2733 & 707 & $9466^{*}$ \\
\hline \multicolumn{7}{|c|}{ Retirement assets other than $401(\mathrm{k})$} \\
\hline Eligible & 18634 & 24539 & 40746 & 46996 & 83533 & 180000 \\
\hline Ineligible & 15326 & 22738 & 37827 & 50338 & 73270 & 146859 \\
\hline Difference & 3308 & 1801 & 2919 & -3342 & $10263^{*}$ & $33141^{*}$ \\
\hline \multicolumn{7}{|c|}{ Total retirement assets } \\
\hline Eligible & 20701 & 34170 & 50492 & 60263 & 101524 & 240902 \\
\hline Ineligible & 14580 & 22909 & 37862 & 50748 & 73814 & 145626 \\
\hline Difference & 6120 & $11261^{*}$ & $12631^{*}$ & 9515 & $27709^{*}$ & $95276^{*}$ \\
\hline \multicolumn{7}{|l|}{ Net housing equity } \\
\hline Eligible & 35135 & 37248 & 45641 & 42496 & 59043 & 83409 \\
\hline Ineligible & 21596 & 32854 & 45233 & 48861 & 55350 & 79517 \\
\hline Difference & $13539^{*}$ & 4393 & 409 & -6365 & 3693 & 3891 \\
\hline \multicolumn{7}{|l|}{ DB coverage } \\
\hline Eligible & 0.29 & 0.42 & 0.5 & 0.53 & 0.66 & 0.74 \\
\hline Ineligible & 0.2 & 0.35 & 0.53 & 0.54 & 0.63 & 0.61 \\
\hline
\end{tabular}


Figure 1. Ratio of Private and Total Retirement Assets to Wage and Salary Earnings

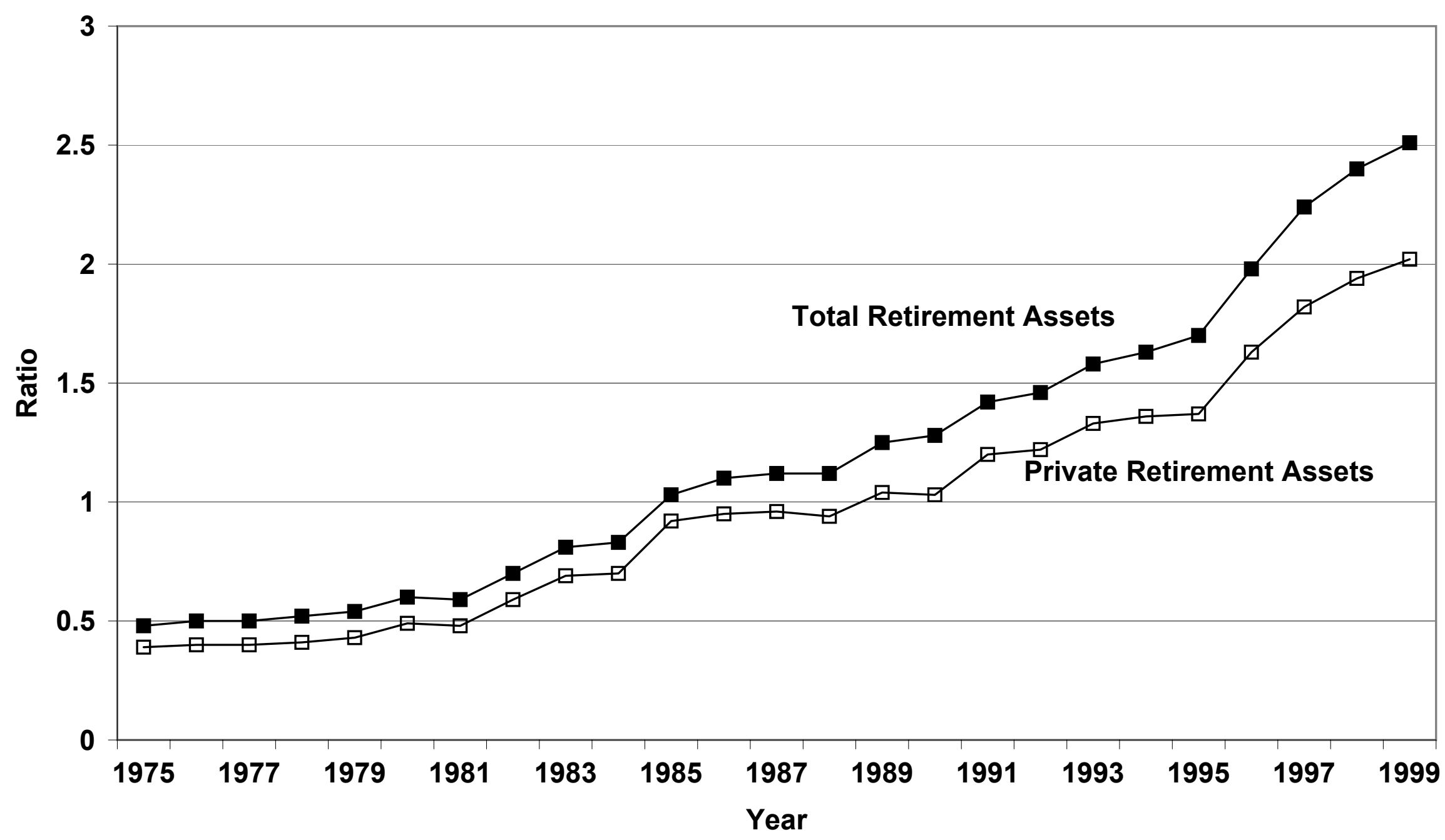


Figure 2. Private Retirement Assets

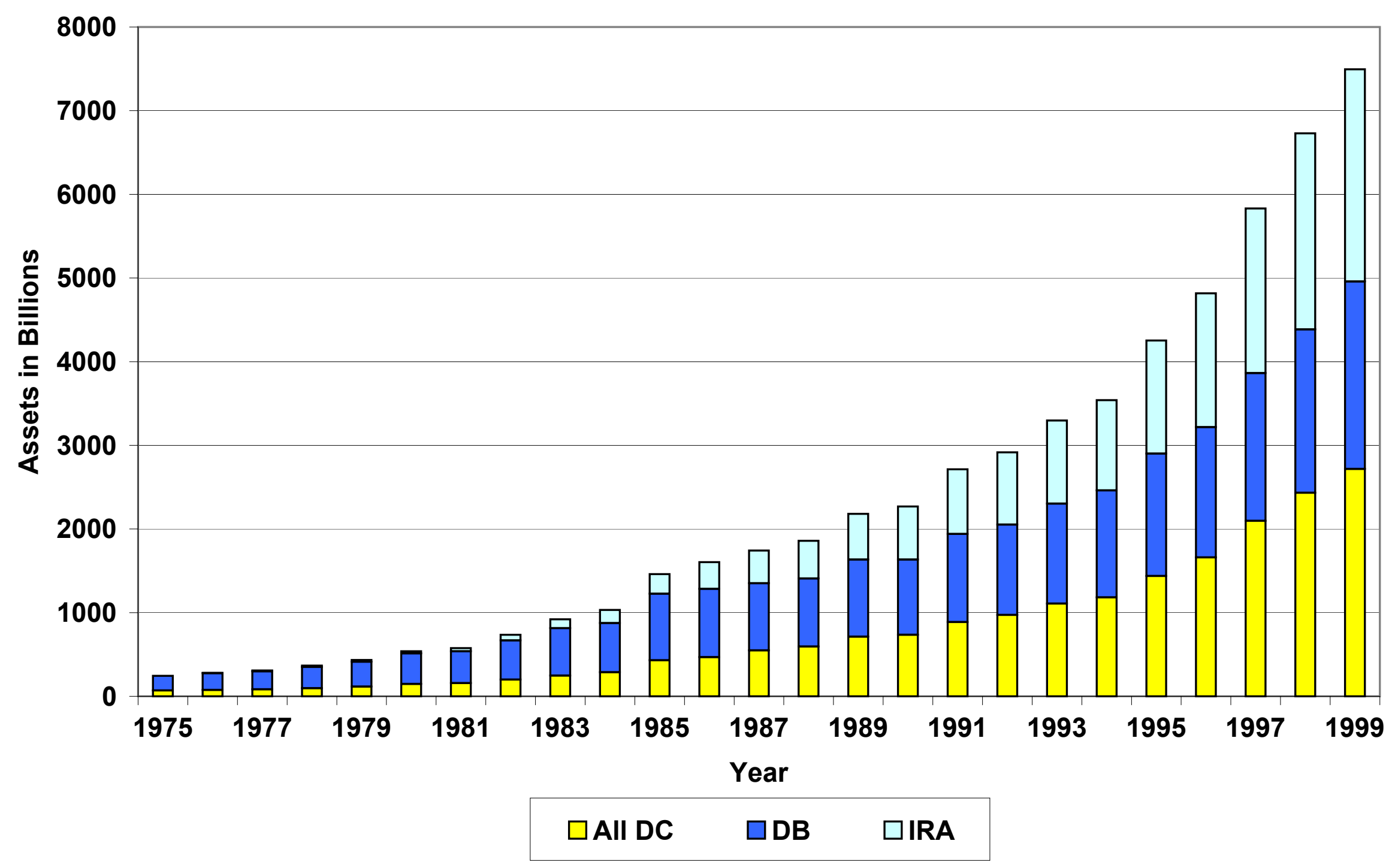


Figure 3. Public and Private Retirement Assets

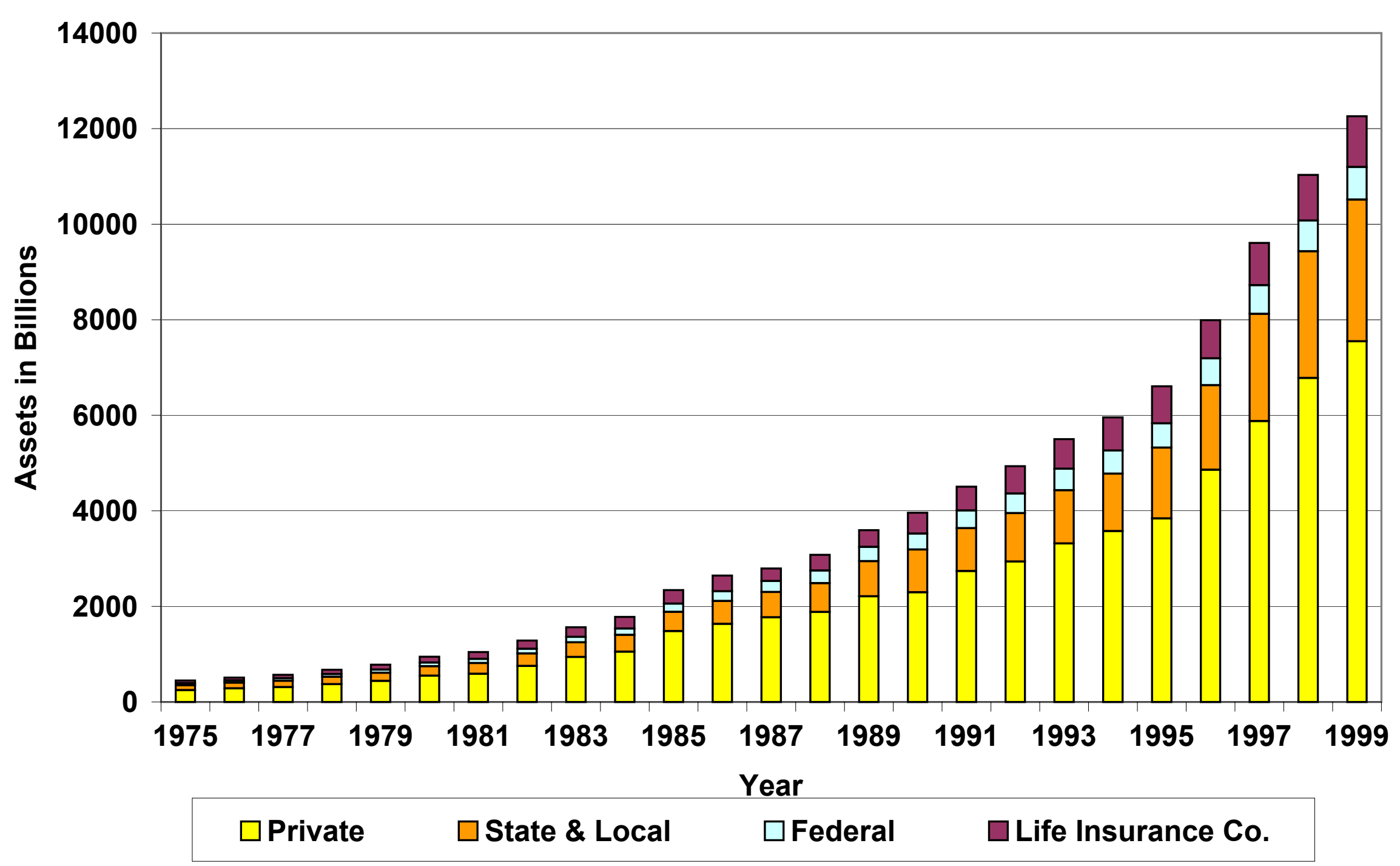


Figure 4. Ratio of Home Equity and Other Assets to Disposable Income

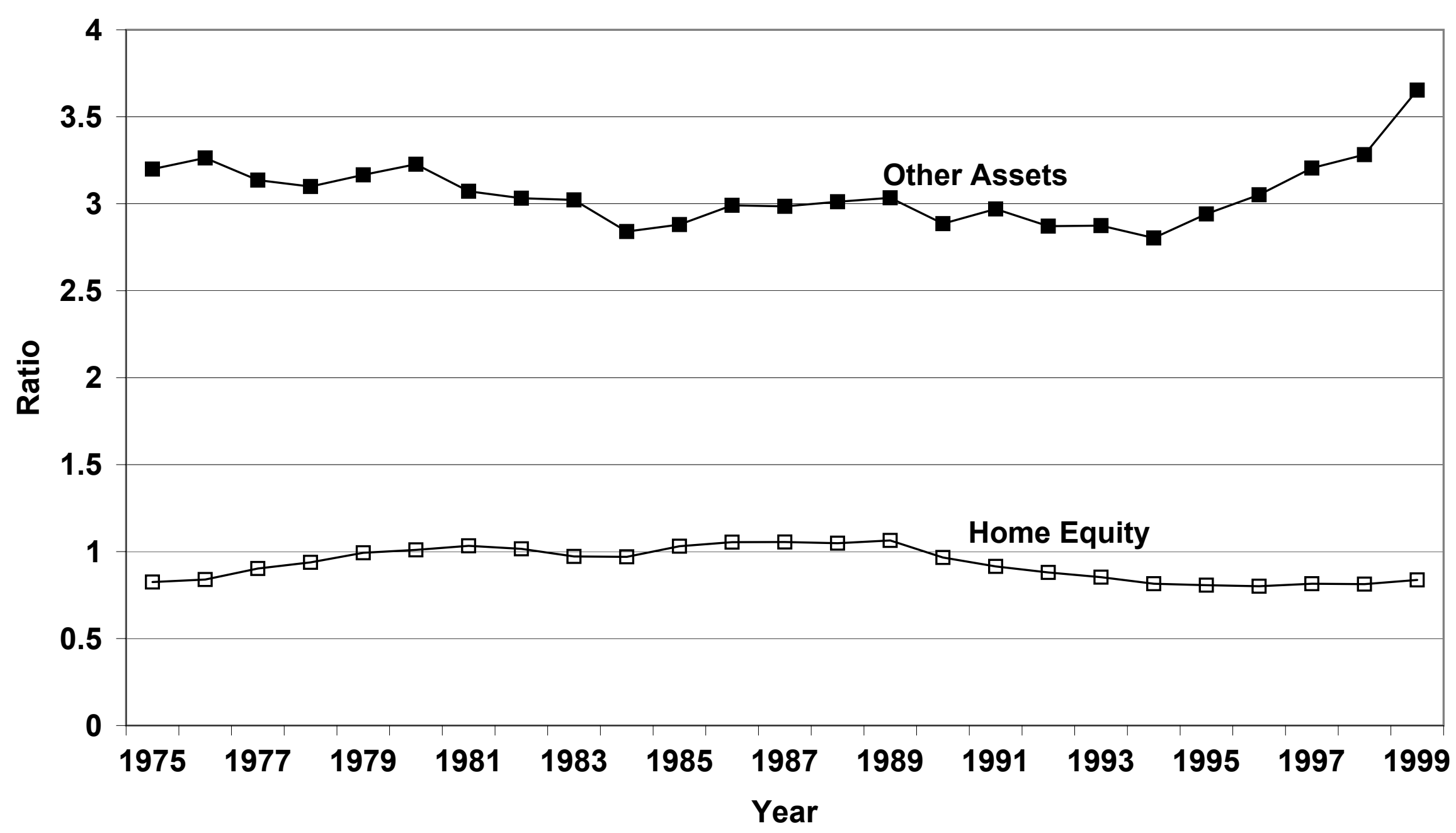


Figure 5a. Private Pension Contributions

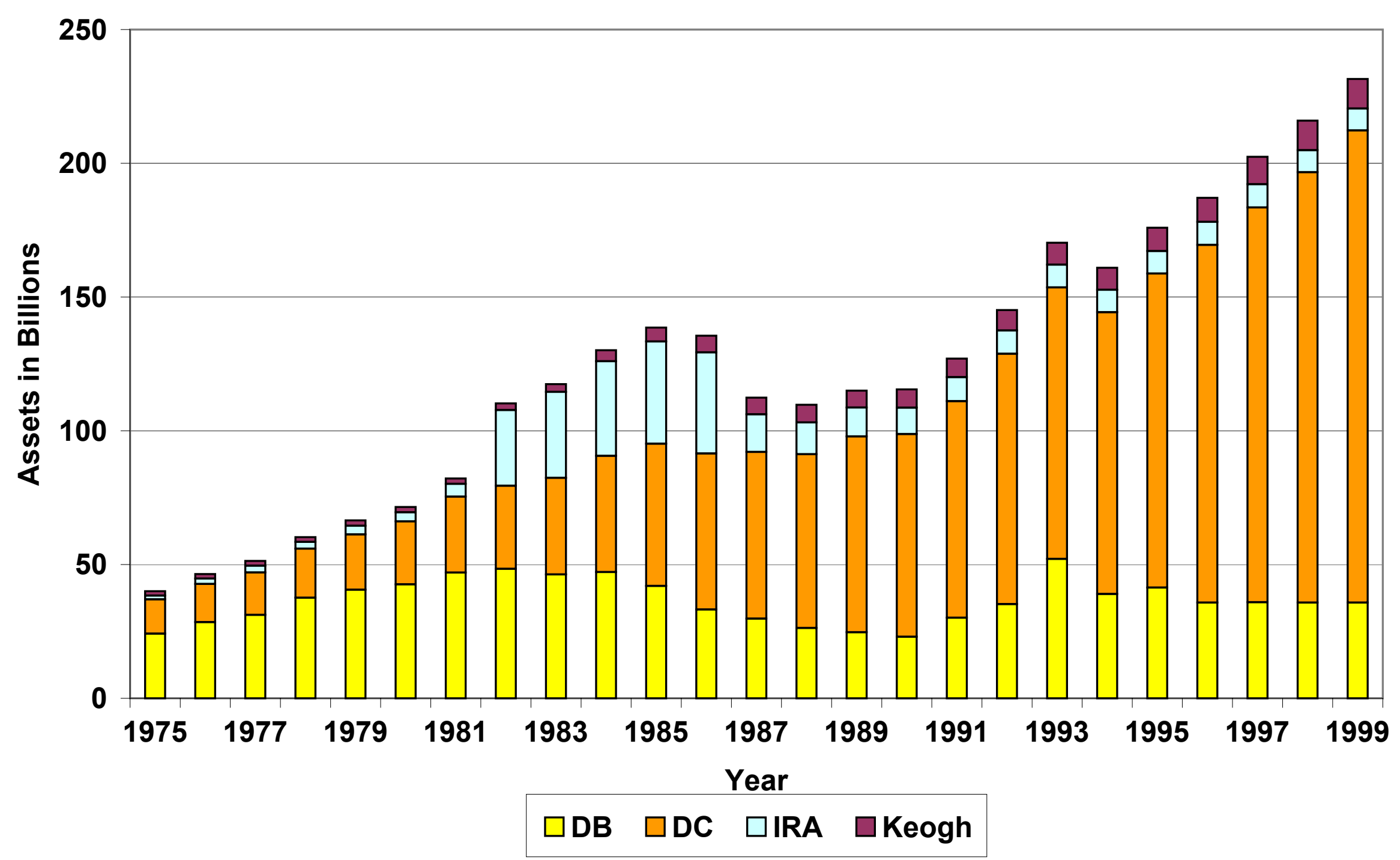


Figure 5b. All Pension Contributions

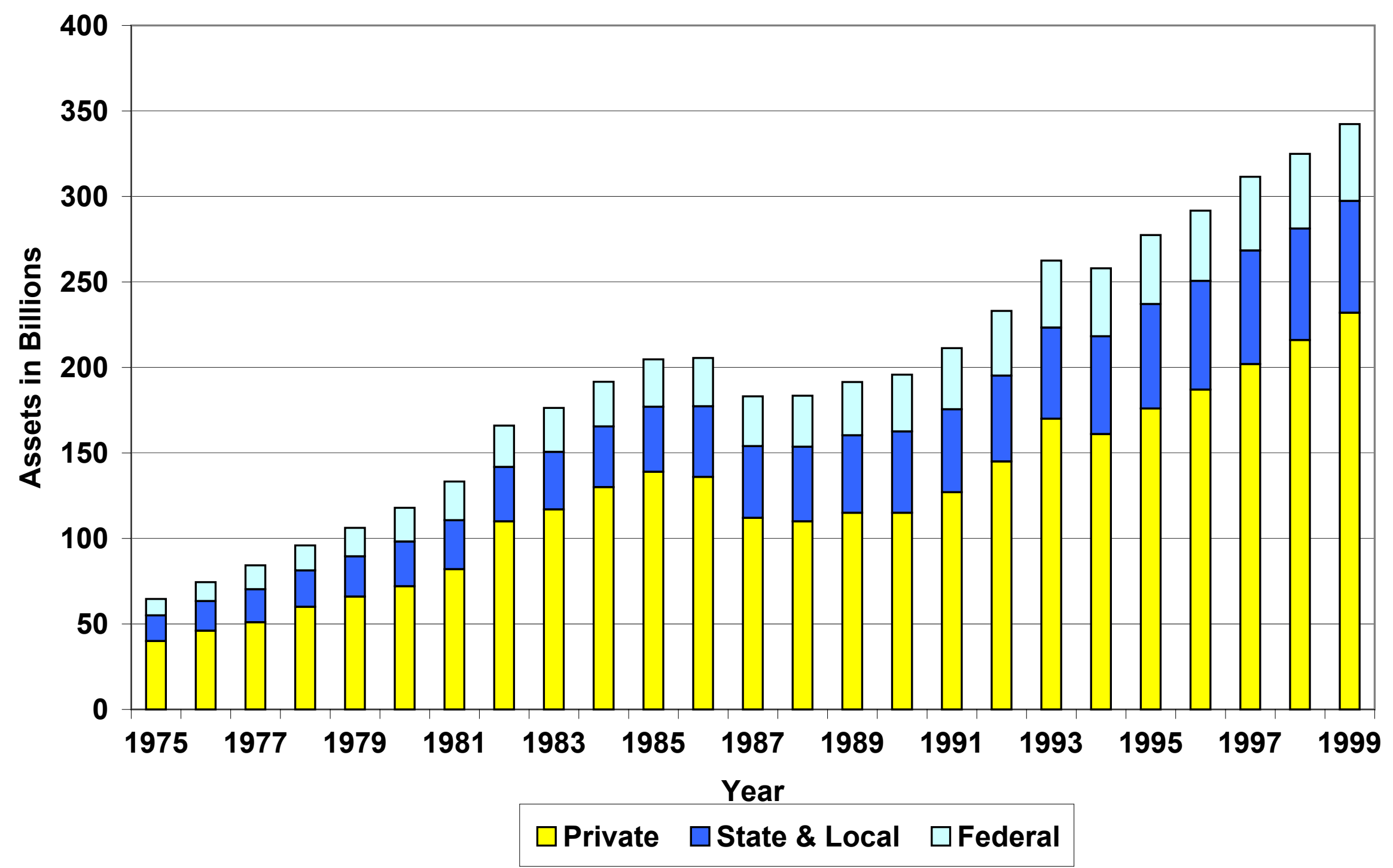


Figure 6a. Ratio of Private and Total Pension Contributions to Disposable Income

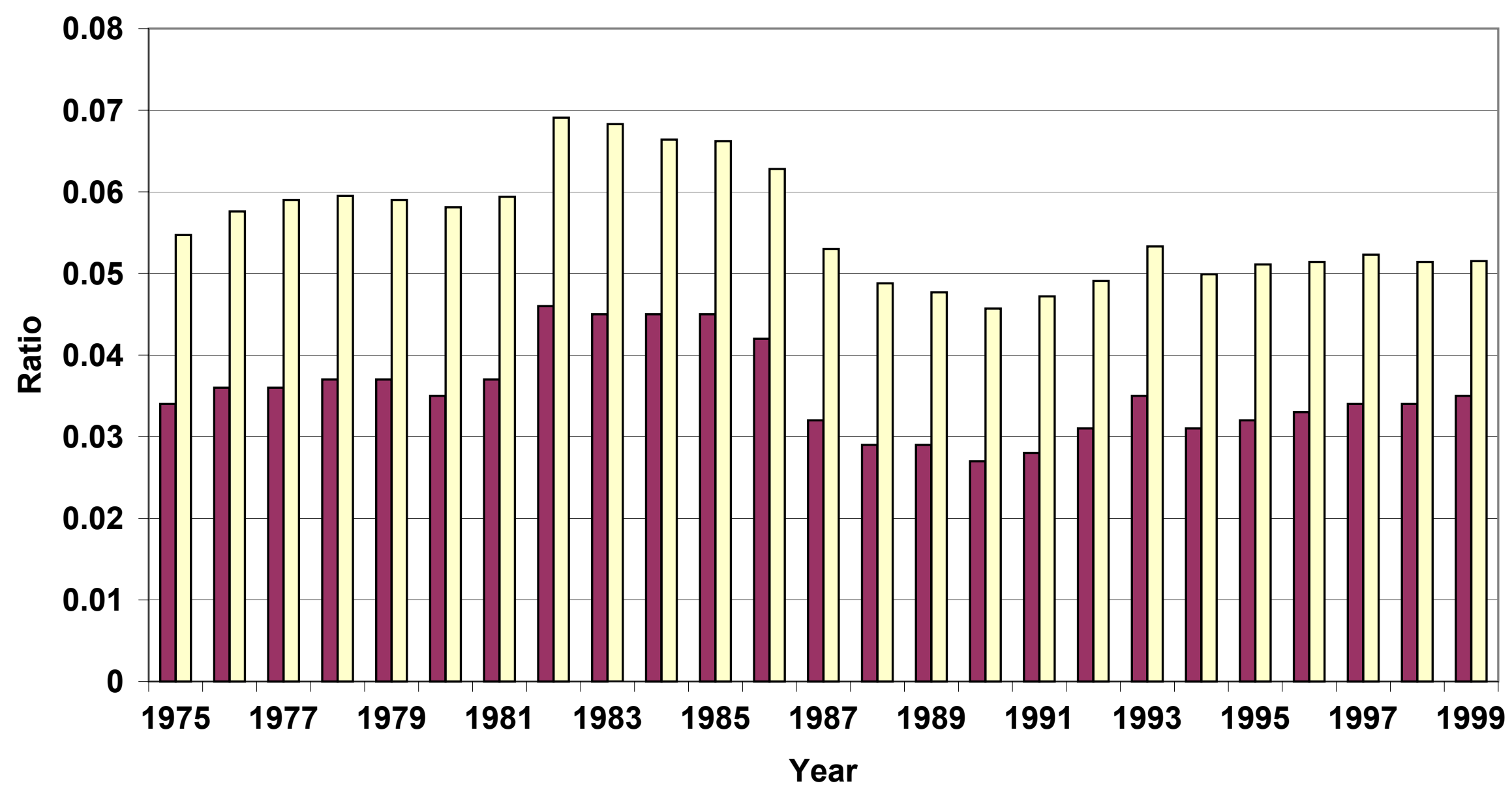

$\square$ Private $\square$ Total 
Figure 6b. Ratio of Private and Total Pension Contributions to Wage and Salary Earnings

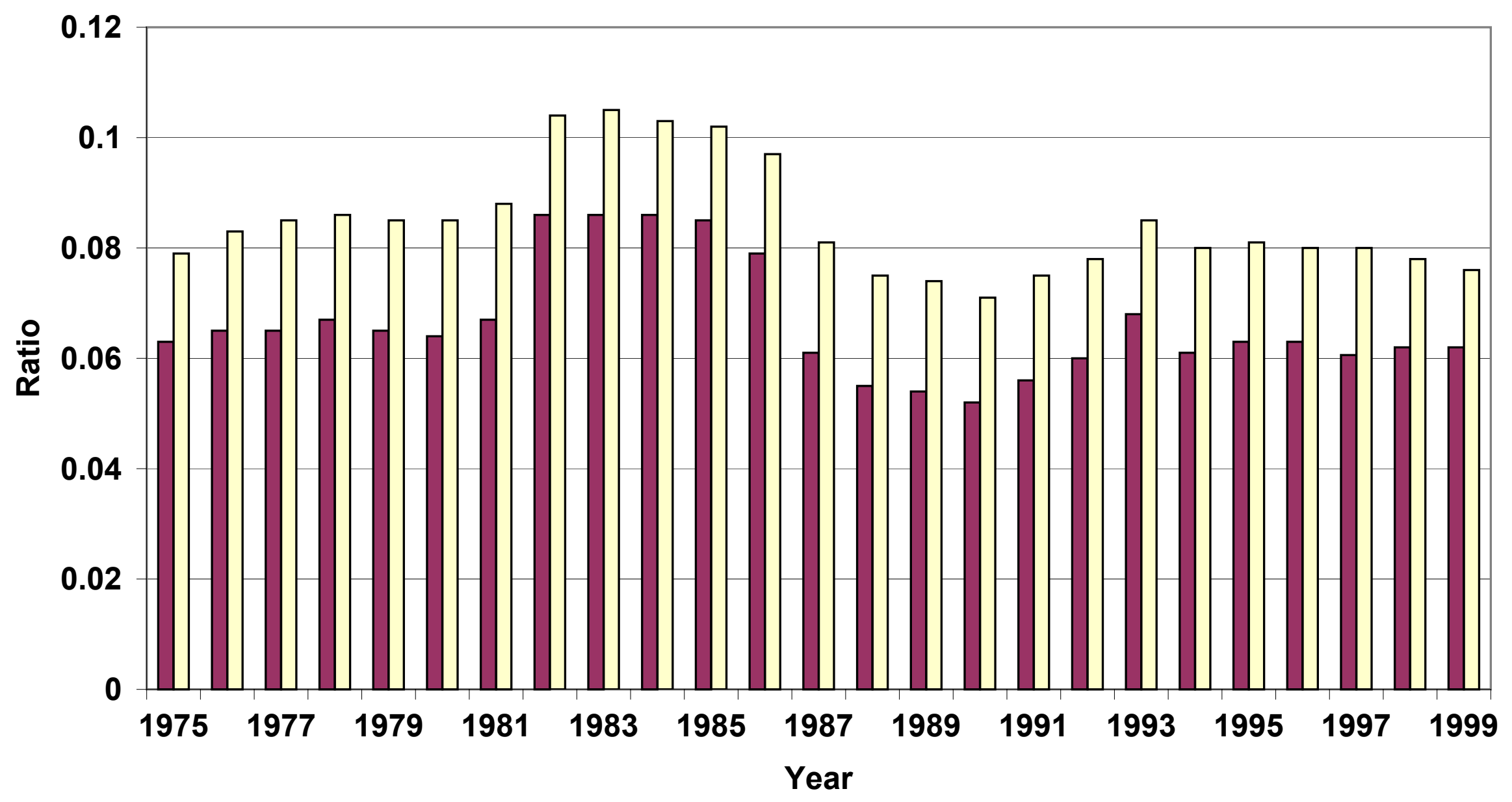

$\square$ Private Contributions/Private W\&S $\square$ Total Contributions/Total W\&S 
Figure 7. Active Participants in Private Pension Plans (with double counting)

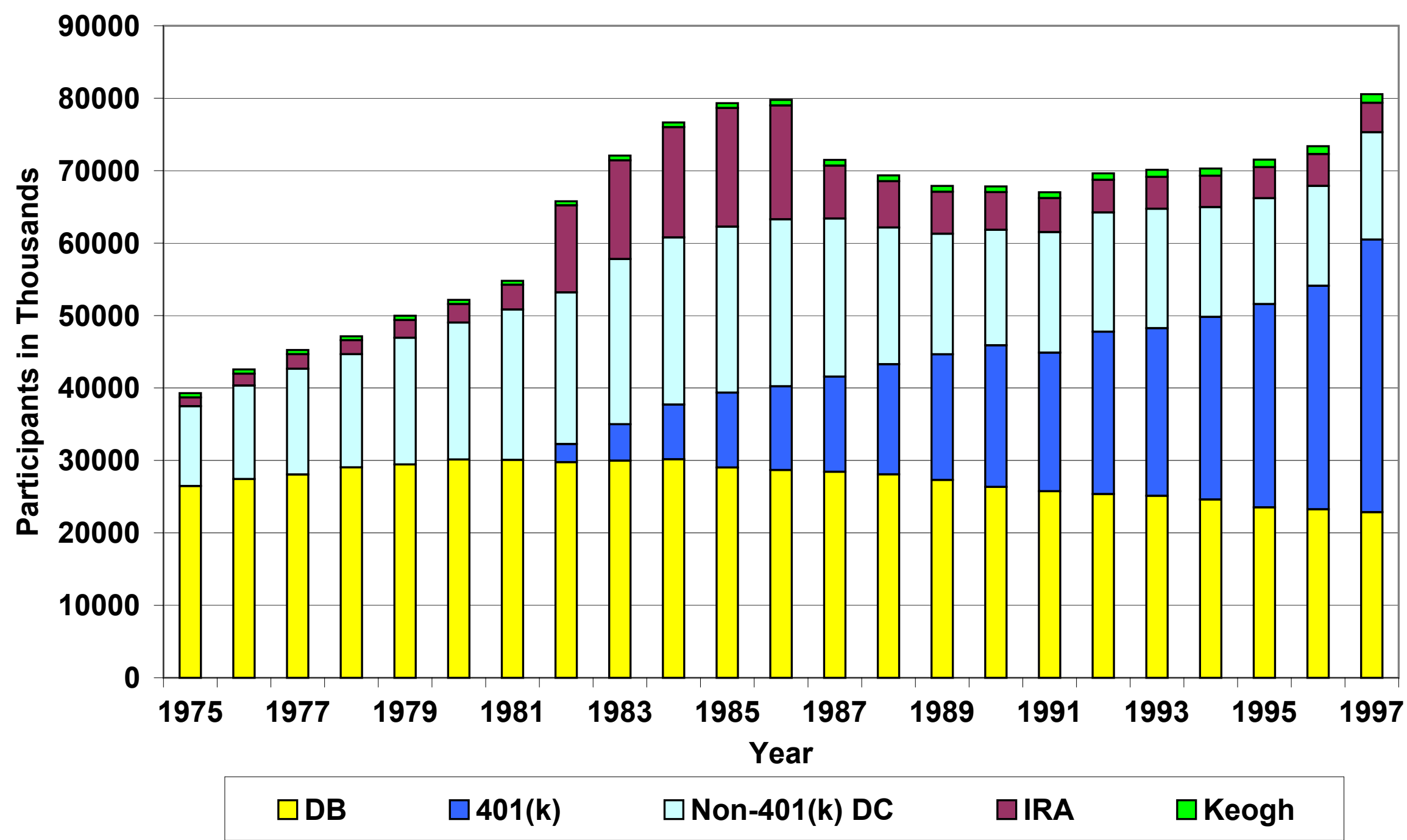


Figure 8a. Contributions per Active Participant DB, DC, and 401(k)

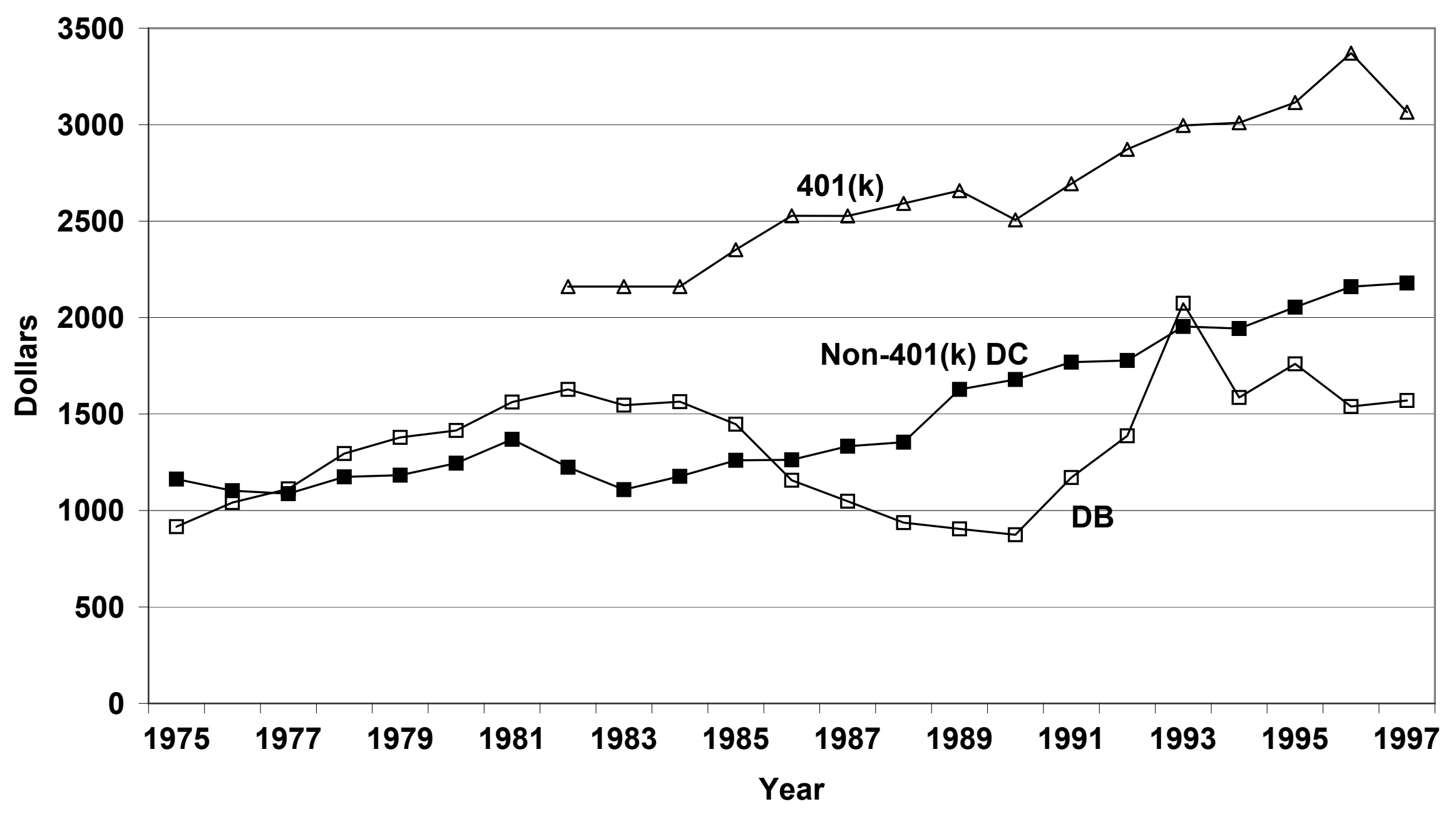


Figure $\mathbf{8 b}$. Contributions per Active Participant IRA and 401(k)

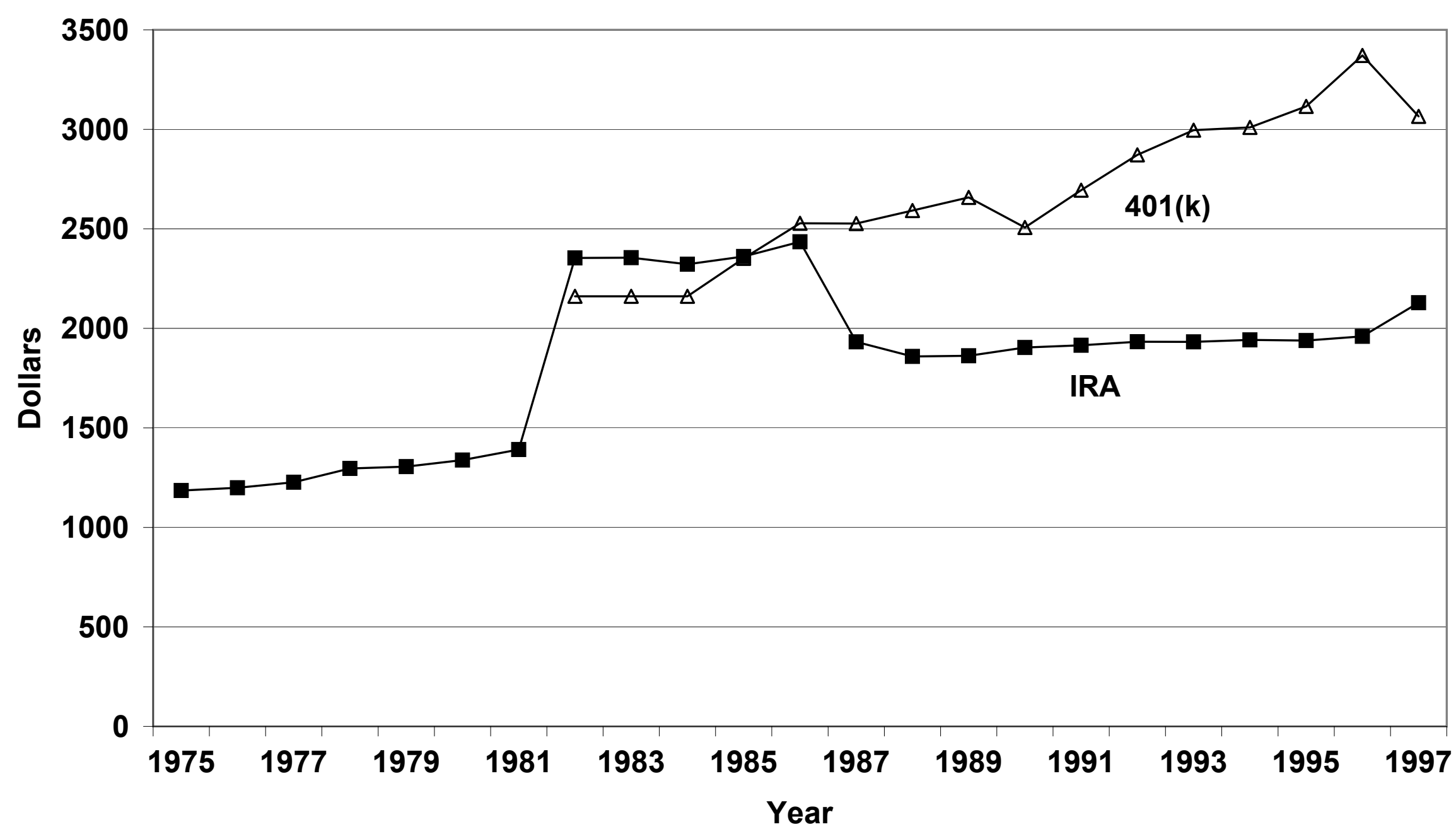


Figure 8c. Contributions per Active Participant Keogh

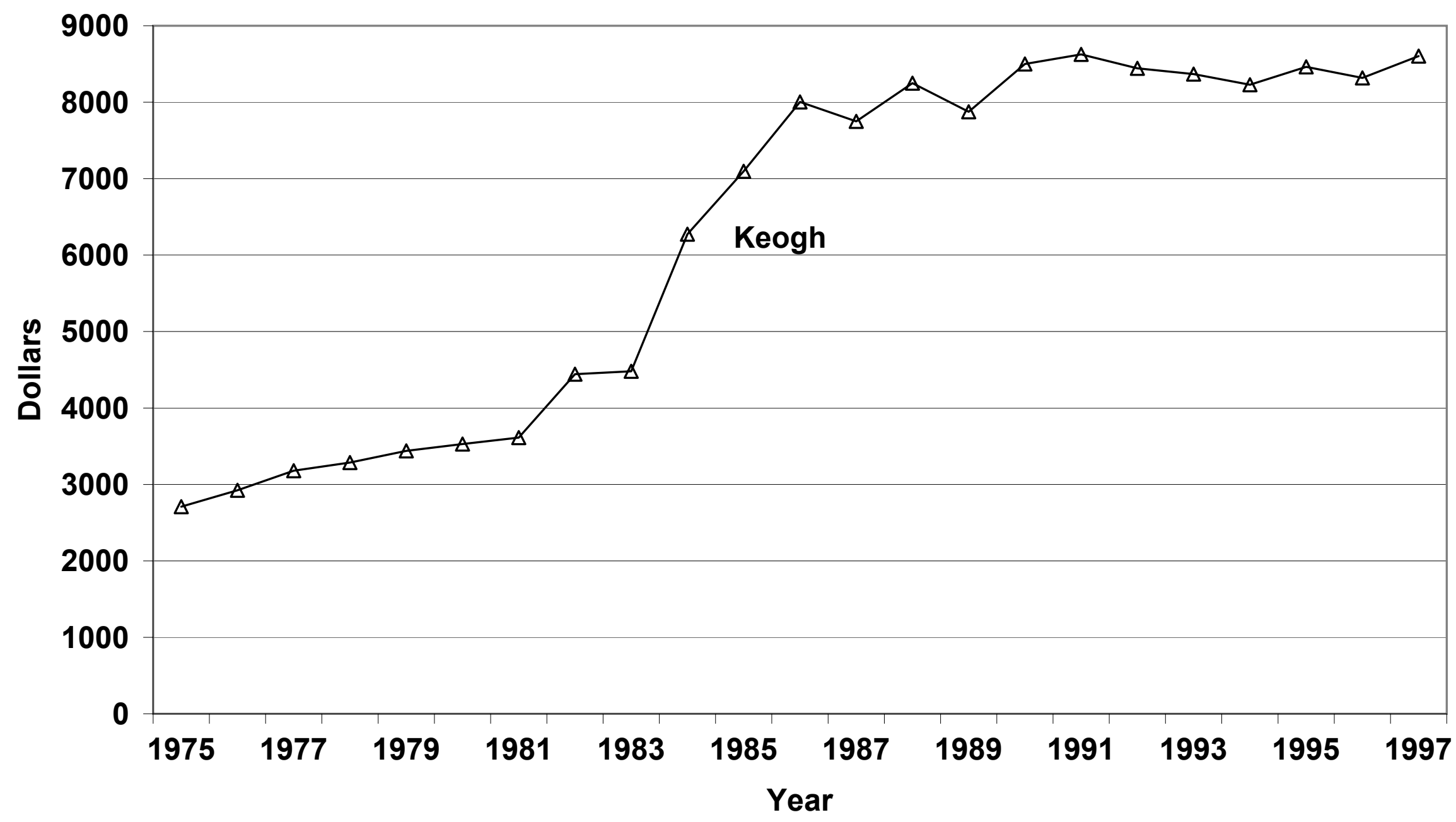


Figure 9. Participants and Contributions per

Participant for All Plans

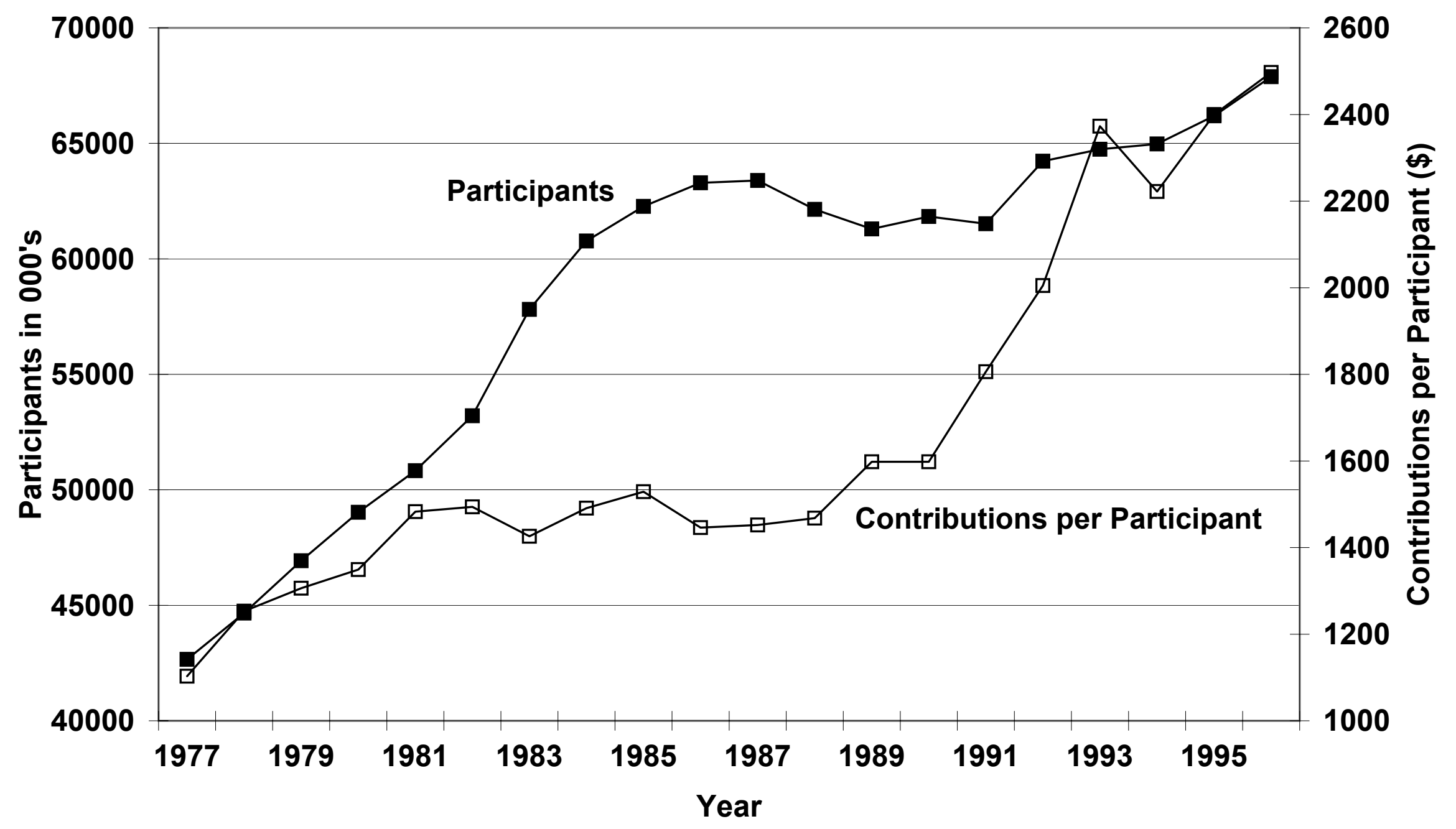


Figure 10. DB Contributions, Participants, and Contributions per Participant (Index: 1977=1)

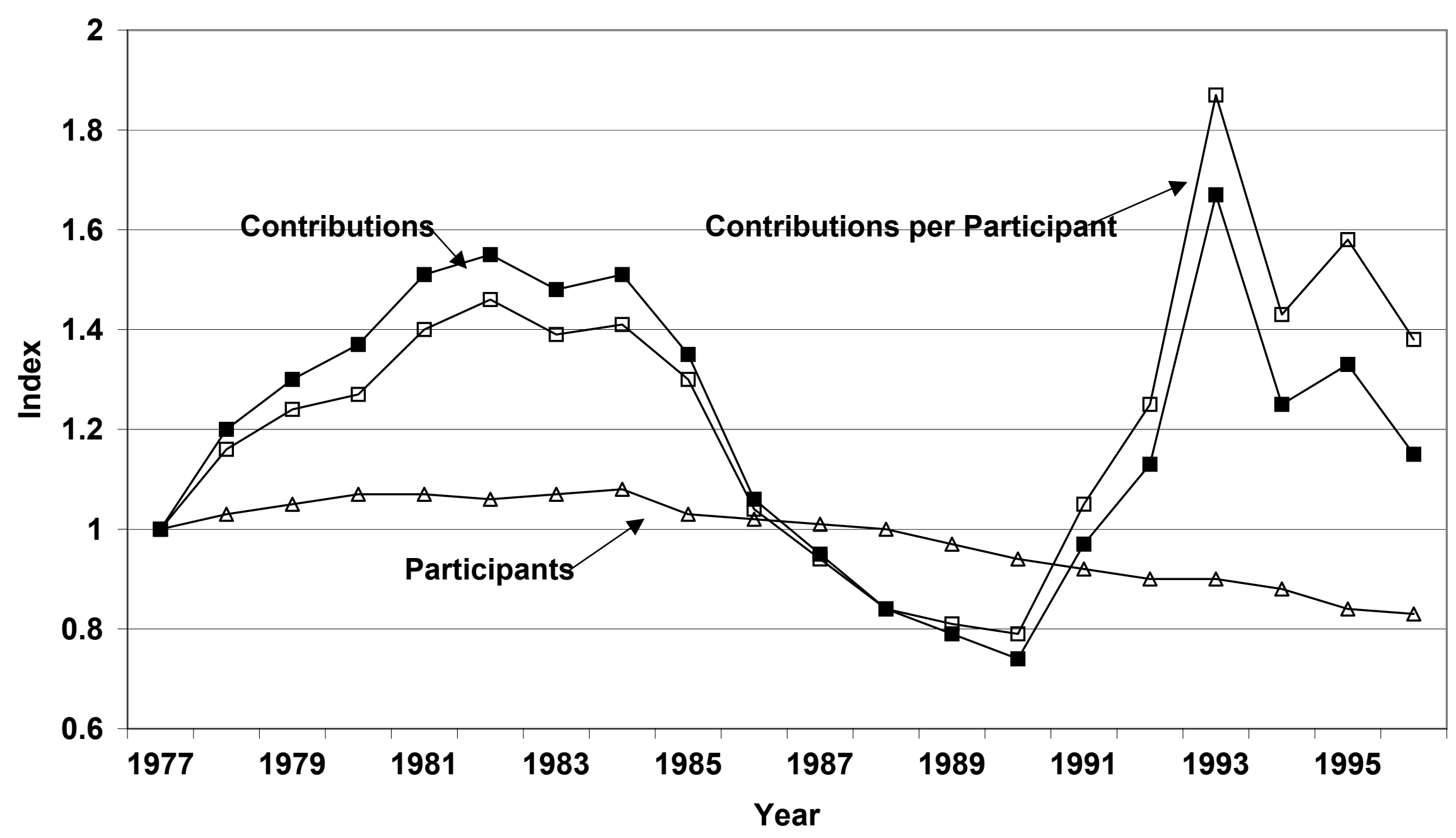


Figure 11. Contributions per Participant (Index: 1977=1)

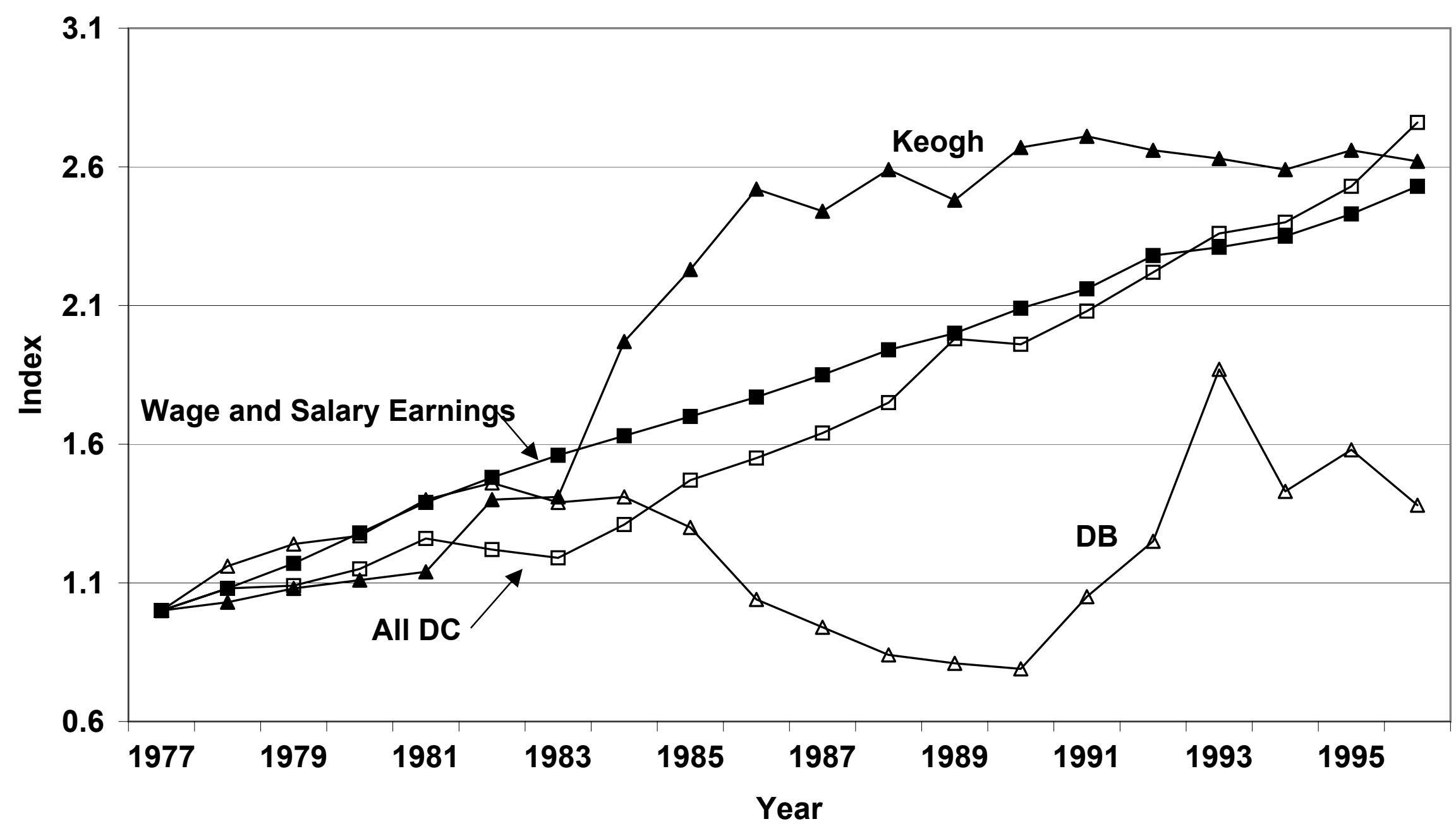


Figure 12. Ratio of Private and DB Adjusted Pension Contributions to Wage and Salary Earnings

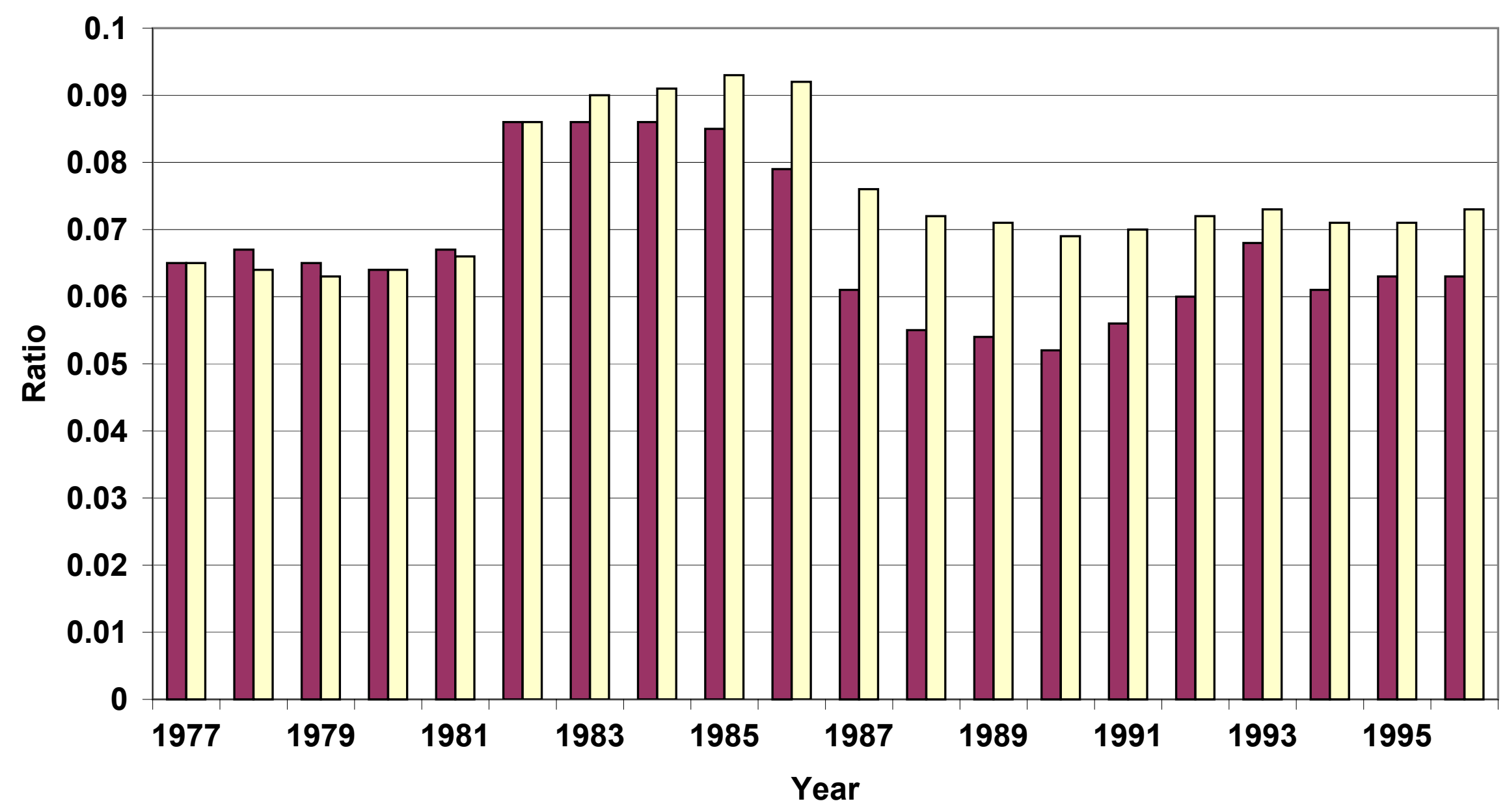

$\square$ Private Contributions/Private W\&S $\square$ DB Adjusted/Private W\&S 
Figure 13. DB Contributions and Benefits

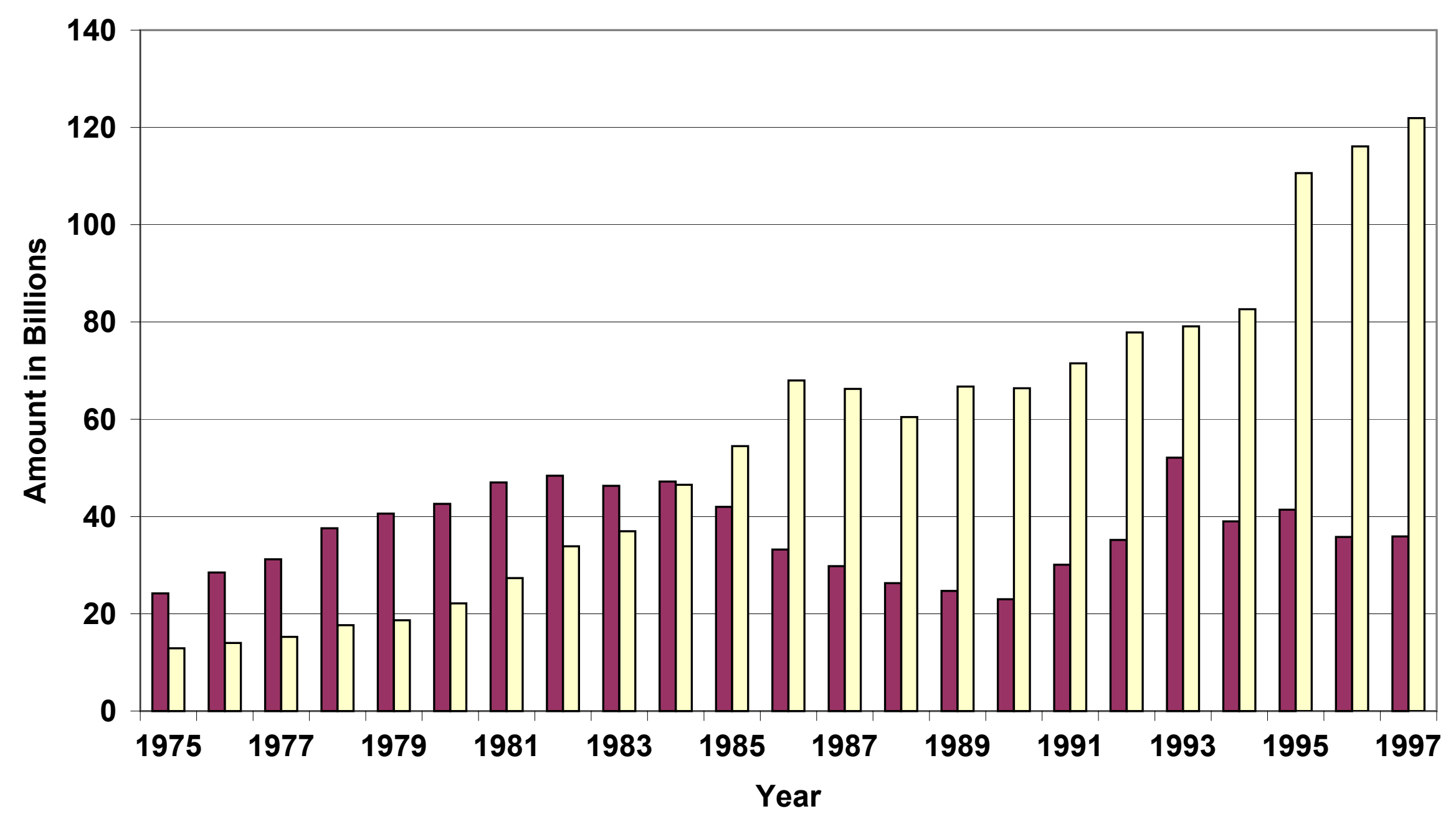

$\square$ Contributions $\square$ Benefits 
Figure 14. IRA Contributions and Benefits



$\square$ Contributions $\square$ Benefits 
Figure 15. Ratio of DB and 401(k) Saving to Earnings

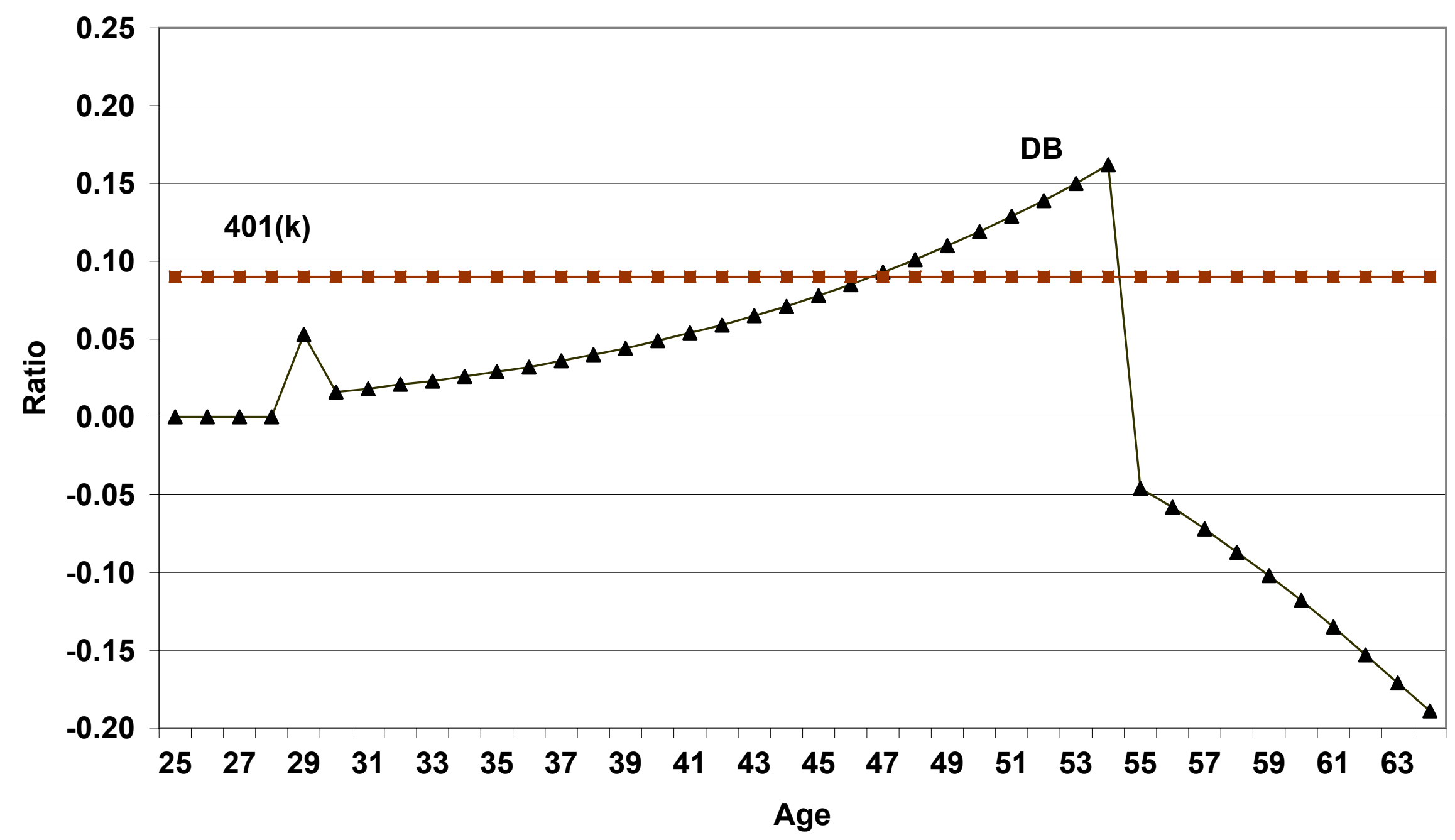


Figure 16. DB and 401(k) Saving Increment to Wealth (Retirement at Age 55)

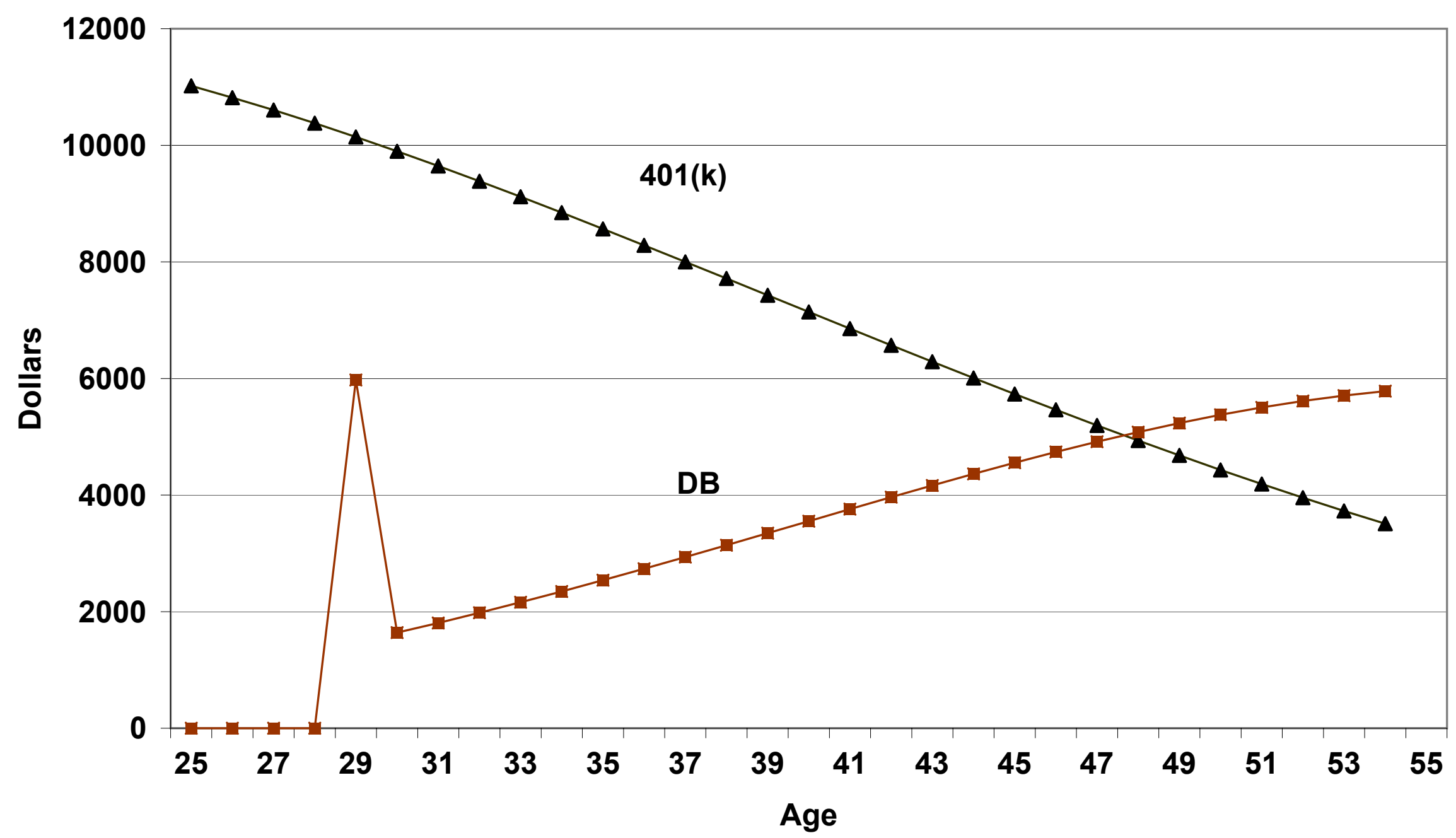


Figure 17. DB and 401(k) Saving Increment to Wealth (Retirement at Age 65)

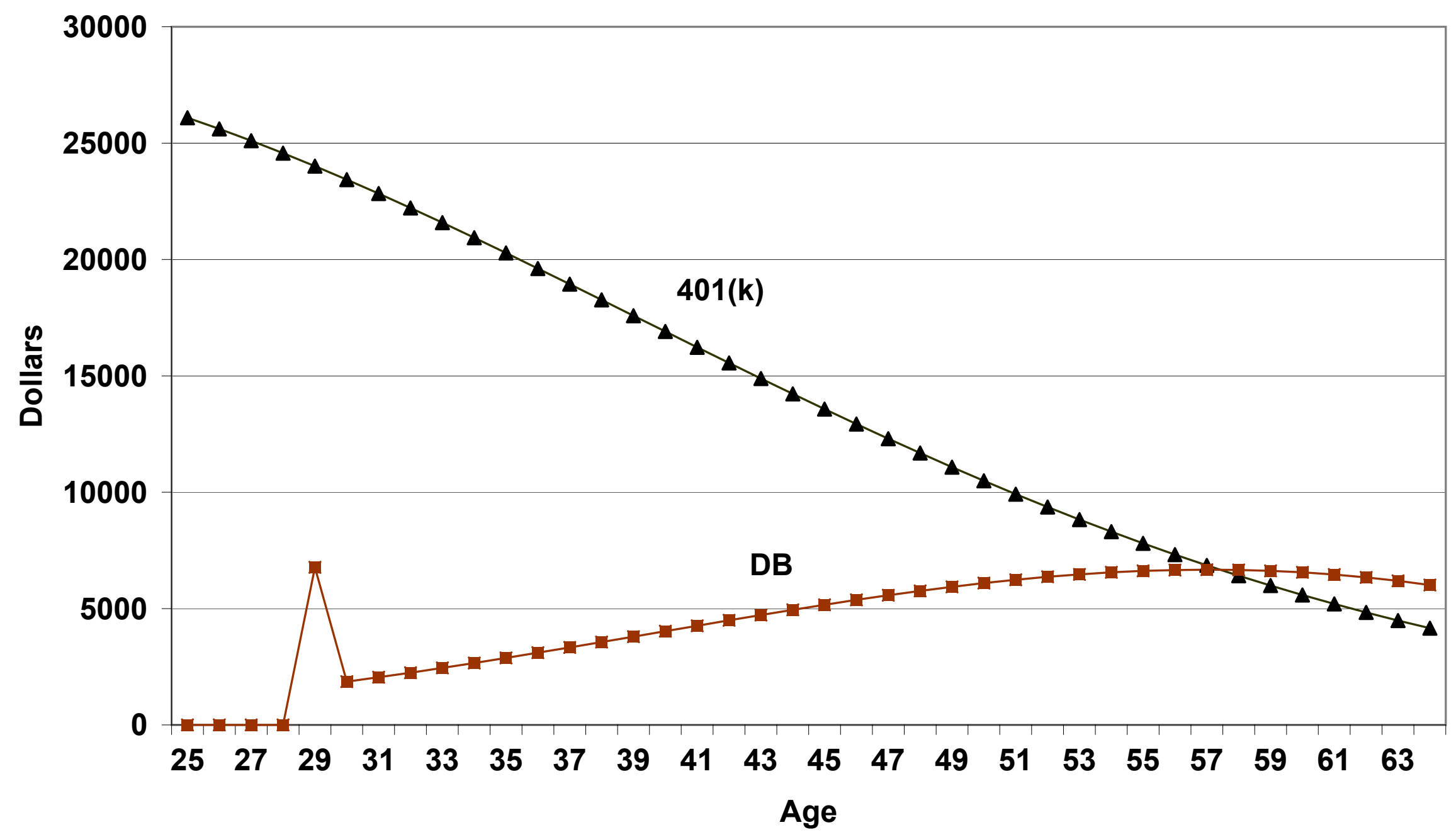


Figure 18. Ratio of Plan Participants to Private Wage and Salary Employment, with Double Counting




Figure 19. DB Participation and 401(k) Eligibility:

\section{Data for Three Cohorts}

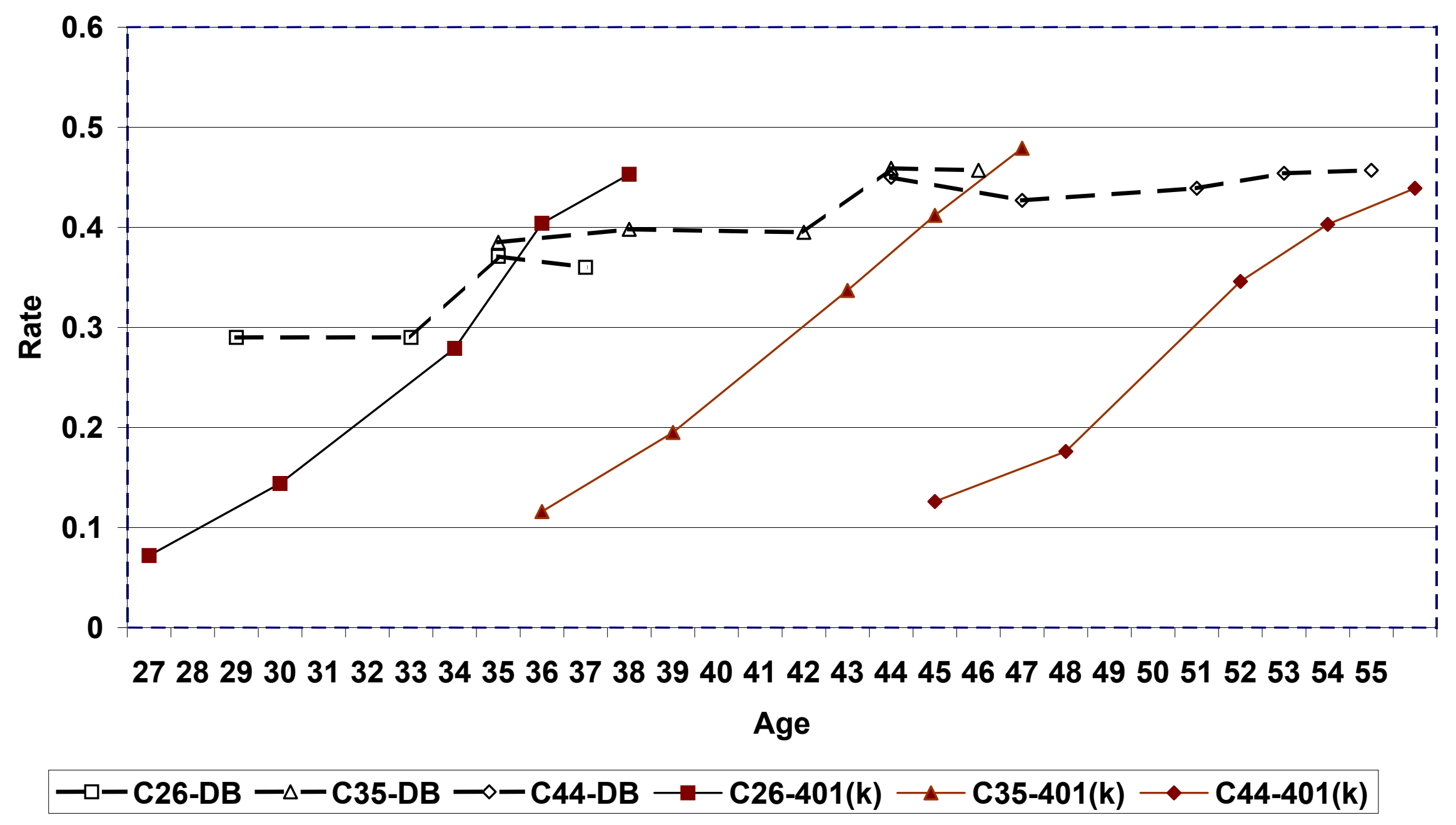

